\title{
It's MORe exciting than mu: crosstalk between mu opioid receptors and glutamatergic transmission in the mesolimbic dopamine system
}

\author{
Elena H. Chartoff* and Hilary S. Connery \\ Department of Psychiatry, Harvard Medical School, McLean Hospital, Belmont, MA, USA
}

\author{
Edited by: \\ Pietro Marini, University of Aberdeen, \\ UK \\ Reviewed by: \\ Mariela Fernanda Perez, Universidad \\ Nacional de Cordoba, Argentina \\ Jean Bidlack, University of Rochester \\ School of Medicine and Dentistry, \\ USA \\ ${ }^{*}$ Correspondence: \\ Elena H. Chartoff, Department of \\ Psychiatry, Harvard Medical School, \\ McLean Hospital, 115 Mill Street, \\ Belmont, MA 02478, USA \\ e-mail: echartoff@mclean.harvard.edu
}

Opioids selective for the $\mathrm{G}$ protein-coupled mu opioid receptor (MOR) produce potent analgesia and euphoria. Heroin, a synthetic opioid, is considered one of the most addictive substances, and the recent exponential rise in opioid addiction and overdose deaths has made treatment development a national public health priority. Existing medications (methadone, buprenorphine, and naltrexone), when combined with psychosocial therapies, have proven efficacy in reducing aspects of opioid addiction. Unfortunately, these medications have critical limitations including those associated with opioid agonist therapies (e.g., sustained physiological dependence and opioid withdrawal leading to high relapse rates upon discontinuation), non-adherence to daily dosing, and non-renewal of monthly injection with extended-release naltrexone. Furthermore, current medications fail to ameliorate key aspects of addiction such as powerful conditioned associations that trigger relapse (e.g., cues, stress, the drug itself). Thus, there is a need for developing novel treatments that target neural processes corrupted with chronic opioid use. This requires a basic understanding of molecular and cellular mechanisms underlying effects of opioids on synaptic transmission and plasticity within reward-related neural circuits. The focus of this review is to discuss how crosstalk between MOR-associated G protein signaling and glutamatergic neurotransmission leads to immediate and long-term effects on emotional states (e.g., euphoria, depression) and motivated behavior (e.g., drug-seeking, relapse). Our goal is to integrate findings on how opioids modulate synaptic release of glutamate and postsynaptic transmission via $\alpha$-amino-3-hydroxy-5-methyl-4-isoxazolepropionic acid and $\mathrm{N}$-methyl-D-aspartate receptors in the nucleus accumbens and ventral tegmental area with the clinical (neurobehavioral) progression of opioid dependence, as well as to identify gaps in knowledge that can be addressed in future studies.

Keywords: morphine, heroin, AMPA, NMDA, GluR1, opioid withdrawal syndrome, plasticity

\section{INTRODUCTION}

Opioids comprise a class of endogenous, naturally occurring and synthetic compounds that bind to and activate one of three known opioid receptors: mu, delta, and kappa (MOR, DOR, KOR, respectively). All opioids possess analgesic properties, which humans have taken advantage of for thousands of years. They also have profound effects on physiology and mood that depend on the specific opioid receptor and site of action in the brain. Opiates, a subclass of opioids that are natural derivatives of the opium plant, papaver somniferum, include morphine and codeine, which are the two major metabolites of heroin. These compounds primarily activate MORs to produce euphoria that can motivate repeated self-administration, produce tolerance, dependence, and ultimately opioid addiction. One percent of all Americans meet criteria for having an opioid use disorder (OUD); heroin use has doubled since 2007, and 2\% of all Americans age 12 and older report misuse of a prescription opioid analgesic within the past 30 days (NSDUH, 2013). In 2008, there were 15,000 accidental overdose deaths related to prescription opioid use alone (Center for Disease Control) and opioid analgesics are second only to marijuana as the first illicit drug reported taken by 1.9 million youth and older adult Americans (NSDUH, 2013). The partial MOR agonist buprenorphine combined with the diversion-preventing opioid receptor antagonist naloxone has been partially successful in engaging youth and adults with OUD into abstinence-focused treatment (Fudala et al., 2003; Mattick et al., 2008; Woody et al., 2008; Weiss et al., 2011). However, controlled data on longer-term outcomes is lacking and patients taking agonist therapies (e.g. the long-lasting, full MOR agonist methadone and buprenorphine) have high rates of relapse (>75\%) upon medication withdrawal (Woody et al., 2008; Weiss et al., 2011).

In fact, the treatment course of OUD is primarily challenged by the experience of the opioid withdrawal syndrome (OWS), which is characterized by both a typical physical syndrome occurring acutely (24-48 h post-withdrawal) and also by an affective/cognitive syndrome of dysphoria, anxiety, irritability, and preoccupation with cravings to use opioids (Kreek and Koob, 1998). These affective withdrawal symptoms occur acutely, but they frequently have a protracted course in humans (Dole et al., 
1966; Martin and Jasinski, 1969; see Table 1). Acute and protracted OWS is observed in controlled studies and in clinical practice to precipitate resumed opioid use; this is not only true for those first entering treatment and inexperienced in recovery practices but also true for those in longer-term recovery on agonist therapy who experience OWS during attempts to discontinue agonist therapy (Magura and Rosenblum, 2001; Woody et al., 2008; Weiss et al., 2011). Therefore, there is a great need to develop newer, medical therapies that are not pharmacologically based on opioids themselves to assist people with OUD in tolerating OWS without relapse to opioid use.

The affective/cognitive components of OWS may be the most important target for drug development, since non-opioid medications (e.g., adrenergic antagonists, anti-emetics, sedativehypnotics) already exist and are widely applied to treat aspects of the physical syndrome. Research in rats demonstrates that naloxone-induced heightened acoustic startle, a pre-clinical proxy for anxiety sensitivity, persists up to 80 days following a single administration of morphine, whereas naloxone-induced conditioned place aversion is not seen after 20 days (Rothwell et al., 2012), suggesting that anxiety may be one of the most persistent protracted symptoms of the OWS. In addition, one clinical study in prescription opioid-dependent individuals suggests that when patients are blinded to buprenorphine taper schedules, their success rates in moving through opioid withdrawal to achieve sustained opioid abstinence may be improved (Sigmon et al., 2013). This could reflect a significant component of anticipatory anxiety about OWS under conditions where individuals are aware of forced reduction.

In order to most successfully treat affective/cognitive components of the OWS, it is imperative to understand how the normal brain processes rewarding and aversive stimuli to modulate behavior, and how opioids subsequently act to change behavior. Excitatory glutamatergic neurotransmission provides a basis for communication between neurons that enables behavior.

Table 1 | Symptoms of unmedicated abstinence in heroin-dependent men*.

\begin{tabular}{lll}
\hline & Days of abstinence \\
\hline Day 3 & Day 10 & Day $\mathbf{3 0}$ \\
\hline - Severe anxiety & $\bullet$ Moderate anxiety & $\bullet$ Mild anxiety \\
- Moderate depression & $\bullet$ Subclinical depression & $\bullet$ Mild depressive \\
& & symptoms \\
- Highest craving & $\bullet$ Moderate craving & $\bullet$ Milder craving \\
- Nasal discharge & $\bullet$ Nasal discharge & $\bullet$ Nasal discharge \\
- Mydriasis & & \\
- Abdominal pain & \\
- Diarrhea & \\
\hline
\end{tabular}

*Based on results of two studies reported by Li etal. (2009) and Shi etal. (2009); anxiety measured by the Hamilton Anxiety Scale (HAM-A), depression by the Beck Depression Inventory (BDI).
Depending on the neural circuits activated, behavior can refer to anticipated stimuli, emotional response, learning (stimulusresponse), or action - all of which become dysfunctional with addiction. The goal of this review is to present and synthesize the current state of knowledge on how activation of MORs modulates glutamatergic neurotransmission through $\alpha$ amino-3-hydroxy-5-methyl-4-isoxazolepropionic acid (AMPA) and $N$-methyl-D-aspartate (NMDA) receptors. We will focus on MOR-glutamate interactions within the mesolimbic dopamine system, a key neural substrate for the affective consequences of acute and chronic opioids. The basic pharmacology, neuroanatomical localization, and physiology of MORs have been well studied in in vitro systems, animal models, and clinical research, and there are numerous comprehensive reviews describing these findings (Law et al., 2000; Williams et al., 2001, 2013; Shalev et al., 2002; Waldhoer et al., 2004; Bailey and Connor, 2005; Pasternak, 2012).

\section{MOR DISTRIBUTION AND ACTIONS}

$\mathrm{Mu}$ opioid receptors are expressed throughout the brain. Several comprehensive studies have been published in which MOR binding sites are mapped (Mansour et al., 1988, 1994; Le Merrer et al., 2009). MORs are generally perisynaptic: they can be localized postsynaptically on dendrites and cell bodies where they regulate neuronal excitability and transduce receptor activation to downstream signal transduction pathways, and they can also be localized presynaptically on axon terminals where they inhibit neurotransmitter release via activation of $\mathrm{K}^{+}$conductance and/or inhibition of $\mathrm{Ca}^{2+}$ conductance (Williams et al., 2001). The cellular and neuroanatomical distribution of MORs is critical for understanding the neural circuits involved in the initiation of opiate action and subsequent plasticity with chronic drug use.

In the context of opiate dependence and withdrawal, several key neuroanatomical substrates have been identified, in particular the reciprocal connections within the limbic subcircuit of corticostriatal circuitry: GABAergic neurons of the nucleus accumbens (NAc), dopaminergic neurons of the ventral tegmental area (VTA), and glutamatergic neurons of the prefrontal cortex (PFC). Importantly, these regions contribute to acute opiate reward, dependence, tolerance, somatic and affective signs of withdrawal, and relapse (Wise, 1989; Stinus et al., 1990; Harris and Aston-Jones, 1994; Bonci and Williams, 1997; LaLumiere and Kalivas, 2008; Chartoff et al., 2009; Shen and Kalivas, 2013). Rats will self-administer opiates directly into the VTA (Bozarth and Wise, 1983; Devine and Wise, 1994), which contains dopaminergic cell bodies, and into the ventral striatum NAc (Olds, 1982), which receives dopaminergic input from the VTA. Acute morphine increases dopamine release in the NAc (Di Chiara and Imperato, 1988b; Johnson and North, 1992) by inhibiting GABAergic neurons in the VTA and rostromedial tegmental nucleus (RMTg) that synapse on dopaminergic neurons (Tepper et al., 1995; Jalabert et al., 2011). Morphine dependence - characterized by physical and psychological withdrawal signs - is mediated by several brain regions, with the locus coeruleus and periaqueductal gray (PAG) region most sensitive to naloxone-precipitated somatic withdrawal symptoms (Koob et al., 1992). The mesolimbic system is also important for morphine dependence, with a key role in affective 
signs of withdrawal: microinjections of naloxone into the NAc causes conditioned place aversions (Koob et al., 1992), and administration of a dopamine $\mathrm{D}_{2}$-like, but not a $\mathrm{D}_{1}$-like, receptor agonist directly into the NAc attenuates somatic withdrawal signs (Harris and Aston-Jones, 1994). Also, dopamine release is decreased in the NAc during morphine withdrawal (Rossetti et al., 1992; Diana et al., 1995; Bonci and Williams, 1997), suggesting that the NAc may mediate certain aspects of morphine dependence. Other key brain regions important for opiate dependence include, but are not limited to, the amygdala, hippocampus, and bed nucleus of the stria terminalis (Mansour et al., 1995b; Gracy et al., 1997).

\section{MOR ACTIVATION AND INTRACELLULAR SIGNALING}

The physiological effects of morphine are absent in mice lacking MORs (Matthes et al., 1996; Le Merrer et al., 2009), providing strong support for the idea that MORs are necessary for the clinically relevant effects of opiates. MORs belong to the G proteincoupled receptor (GPCR) superfamily of seven transmembrane receptors and the rhodopsin receptor subfamily and are linked to pertussis toxin-sensitive inhibitory heterotrimeric guanosine triphosphate-binding proteins $\left(\mathrm{G}_{\alpha \mathrm{i}} / \mathrm{G}_{\alpha \mathrm{o}}\right)$. Overall, MORs, DORs, and KORs are approximately $60 \%$ identical to each other (Chen et al., 1993).

Upon MOR activation, $G$ protein $\alpha$ and $\beta \gamma$ subunits interact with downstream effector systems to inhibit adenylyl cyclase and voltage-gated $\mathrm{Ca}^{2+}$ channels and to stimulate $\mathrm{G}$ protein-activated inwardly rectifying $\mathrm{K}^{+}$channels (GIRKs) and phospholipase C $\beta$ (Childers, 1991; Waldhoer et al., 2004; Williams et al., 2013; see Figures 1 and 2, Naïve condition, for depiction of MORdependent signaling). In the presence of chronic morphine, a compensatory increase in adenylyl cyclase activity occurs and cAMP levels return to normal (see Figures 1 and 2, GABAergic neurons in Naïve, Acute, and Chronic conditions). When morphine is discontinued or withdrawal is pharmacologically precipitated, cAMP levels dramatically increase (see Figures 1 and 2, GABAergic neurons in Withdrawal condition; Nestler and Aghajanian, 1997; Williams etal., 2001). This phenomenon of early inhibition and late positive regulation of adenylyl cyclase by morphine has been demonstrated in several morphine-receptive brain regions (Duman et al., 1988; Nestler and Tallman, 1988; Terwilliger et al., 1991; Van Vliet et al., 1991; Self et al., 1995; Shaw-Lutchman et al., 2002). Upregulation of the cAMP pathway observed during morphine withdrawal activates cAMP-dependent protein kinase A (PKA; Chartoff et al., 2003a,b, 2006). Interestingly, it has been reported that the increase in adenylyl cyclase activity may itself result in a decrease in transcript levels of particular cyclases in the striatum (Spijker et al., 2004).

Protein kinase A phosphorylates and activates numerous substrates, including the transcription factor cAMP response element binding protein (CREB) and the AMPA receptor (AMPAR) subunit GluR1 (Figure 1, Withdrawal condition; Figure 3; Konradi et al., 1994; Chartoff et al., 2003b, 2006; Mangiavacchi and Wolf, 2004). Optimal PKA-mediated increases in CREB and GluR1 signaling requires NMDA receptor (NMDAR) activation (Konradi etal., 1996; Wolf, 2010), providing early evidence for crosstalk between MORs and glutamatergic transmission. It is through these actions that morphine and heroin may ultimately modulate fast excitatory transmission via AMPAR and NMDAR.

\section{GLUTAMATERGIC NEUROTRANSMISSION}

The classic view of glutamate action comprises presynaptic release of glutamate, binding to postsynaptic ionotropic receptors, and clearance of glutamate by $\mathrm{Na}^{+}$-dependent glutamate transporters (Anggono and Huganir, 2012). Layered upon this are the more recently discovered influences of glial-derived glutamate release and uptake and extrasynaptic mGluRs on excitatory synaptic transmission and plasticity (Kalivas et al., 2009). Although this review focuses on MOR-mediated modulation of AMPAR and NMDAR-mediated glutamatergic transmission, it is essential to understand that glutamate homeostasis (regulation of synaptic and perisynaptic extracellular glutamate levels) requires ionotropic and metabotropic (mGluR) receptors as well as a delicate balance between glial and synaptic glutamate release and elimination. Comprehensive reviews of glutamate homeostasis in the context of drug addiction are available (Kalivas, 2009; Kalivas et al., 2009).

\section{AMPA RECEPTORS}

AMPARs are a subgroup of ionotropic glutamate receptors found at most excitatory synapses, are activated at resting membrane potential, and are considered the primary postsynaptic mediators of glutamate transmission in the NAc (Cherubini et al., 1988). AMPARs comprise four subunits (GluR1-4) that assemble in various combinations to form tetramers (Seeburg, 1993; Hollmann and Heinemann, 1994; Dingledine et al., 1999). GluR1-4 share $\sim 70 \%$ sequence homology and differ primarily due to posttranscriptional modifications, which confer unique properties to the subunits. For example, the GluR2 transcript undergoes RNA editing such that a glutamine residue in the channel-forming segment of the receptor is converted to an arginine (Sommer et al., 1991). This renders GluR2-containing AMPARs impermeable to $\mathrm{Ca}^{2+}$ (Burnashev et al., 1992). Given that AMPARs exist primarily as GluR1-2 and GluR2-3 populations (Wenthold et al., 1996), most AMPARs gate $\mathrm{Na}^{+}$but not $\mathrm{Ca}^{2+}$. However, synaptic activity - including in vivo experience - can shift the stoichiometry of synaptic AMPAR subunit composition toward GluR2-lacking receptors (Liu and Cull-Candy, 2000; Takahashi et al., 2003; Ju et al., 2004; Clem and Barth, 2006), and increasing GluR1 expression favors formation of GluR1-homomeric AMPARs that allow $\mathrm{Ca}^{2+}$ flux (Hollmann et al., 1991).

Trafficking of AMPARs into and out of synapses determines the level of excitatory synaptic strength and is a major mechanism of plasticity underlying learning (Malinow and Malenka, 2002). AMPARs can be endocytosed and exocytosed into perisynaptic regions, and they can also be shuttled laterally along the surface of the neuronal membrane between synaptic and extrasynaptic compartments (Heine et al., 2008). A host of AMPAR auxiliary subunits such as transmembrane AMPAR regulatory proteins (TARPs), Cornichon proteins, Neuropilin, and Tolloid-like proteins (Netos) are necessary for the dynamics of AMPAR subcellular localization (Straub and Tomita, 2012). Heteromers containing GluR2-3 subunits are constitutively recycled and maintain basal AMPAR transmission, whereas heteromers containing GluR1-2 


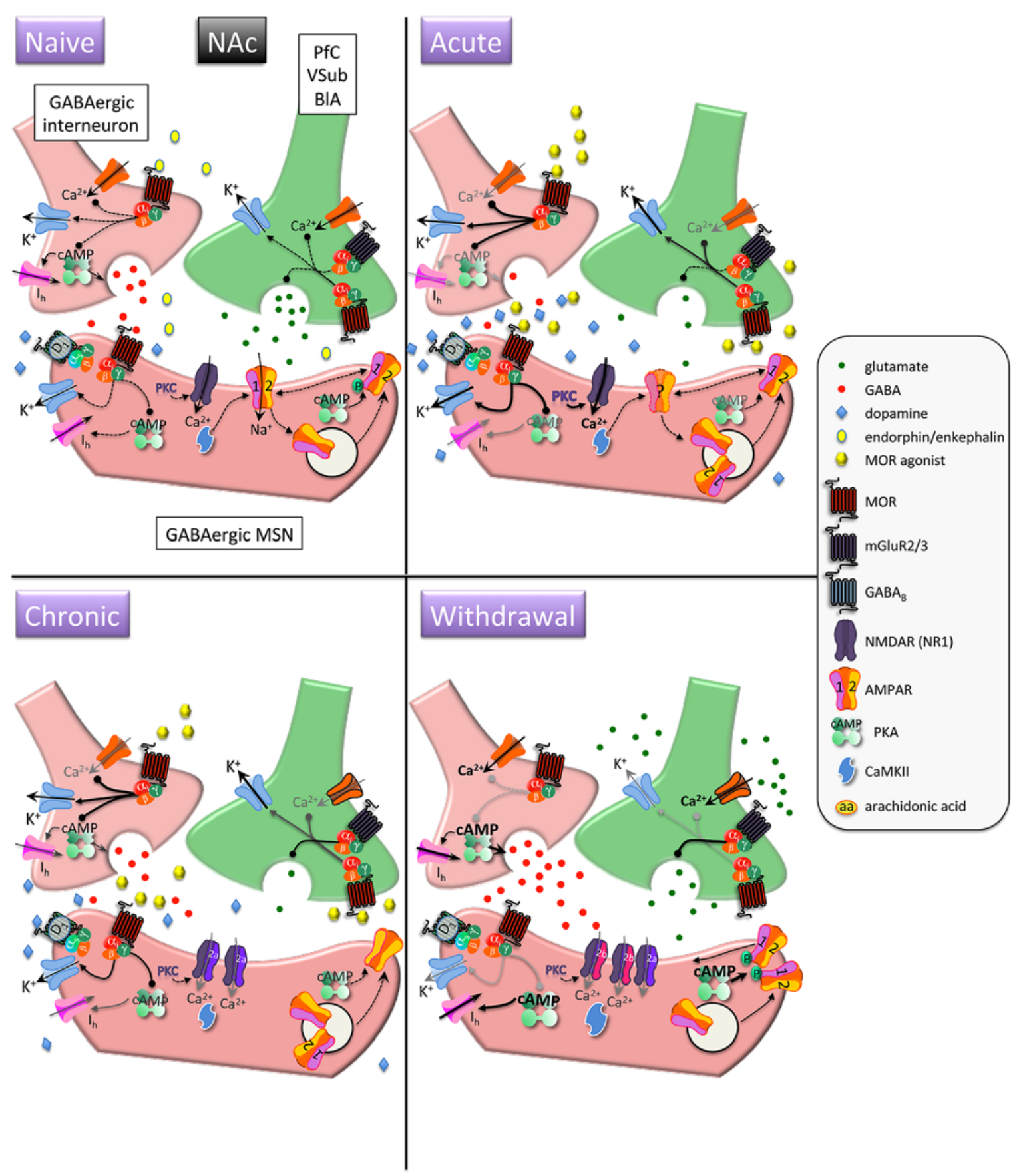

FIGURE 1 | Interactions between MOR and glutamatergic

neurotransmission in the nucleus accumbens (NAc). MORs are coupled to inhibitory $G_{\alpha i}$ proteins and are found on glutamatergic and GABAergic terminals and postsynaptically on (primarily) D1 receptor-expressing MSNs. Acute opioids: Acute MOR activation in a naive animal suppresses GABA and glutamate release via inhibition of $\mathrm{Ca}^{2+}$ and activation of $\mathrm{K}^{+}$conductances, as well as inhibition of CAMP-mediated activation of non-selective cation pacemaker currents $\left(/_{h}\right)$. Postsynaptic NMDAR currents are augmented via MOR-induced PKC activation. There is no known data on the acute, immediate effects of opioids on AMPAR expression/localization/function in naïe animals. Chronic opioids: Inhibitory effect of presynaptic mGluR2/3 receptors to inhibit glutamate release is increased during chronic opioid treatment. Surface expression of GluR1 subunits is decreased on MSNs, with no change in total AMPAR subunit expression. Levels and/or function of the NR2A NMDAR subunit are increased, which may contribute to a decreased affinity for the co-agonist glycine and a decreased sensitivity to PKC-mediated NMDAR activation. Opioid withdrawal: Extracellular glutamate levels are increased, but synaptic transmission may be reduced via enhanced mGluR2/3 autoreceptor function. GABA release is potentiated via augmented cAMP and PKA pathways. NR2B surface expression is increased, perhaps resulting in an increase in silent synapses devoid of AMPARs. Upregulated CAMP and PKA signaling leads to increased P-GluR1 Ser845, which may prime AMPARs containing GluR1 at the plasma membrane to be shuttled to synapse upon CaMKII activation. PfC, prefrontal cortex; VSub, ventral subiculum; BIA, basolateral amygdala; MSN, medium spiny neuron. 


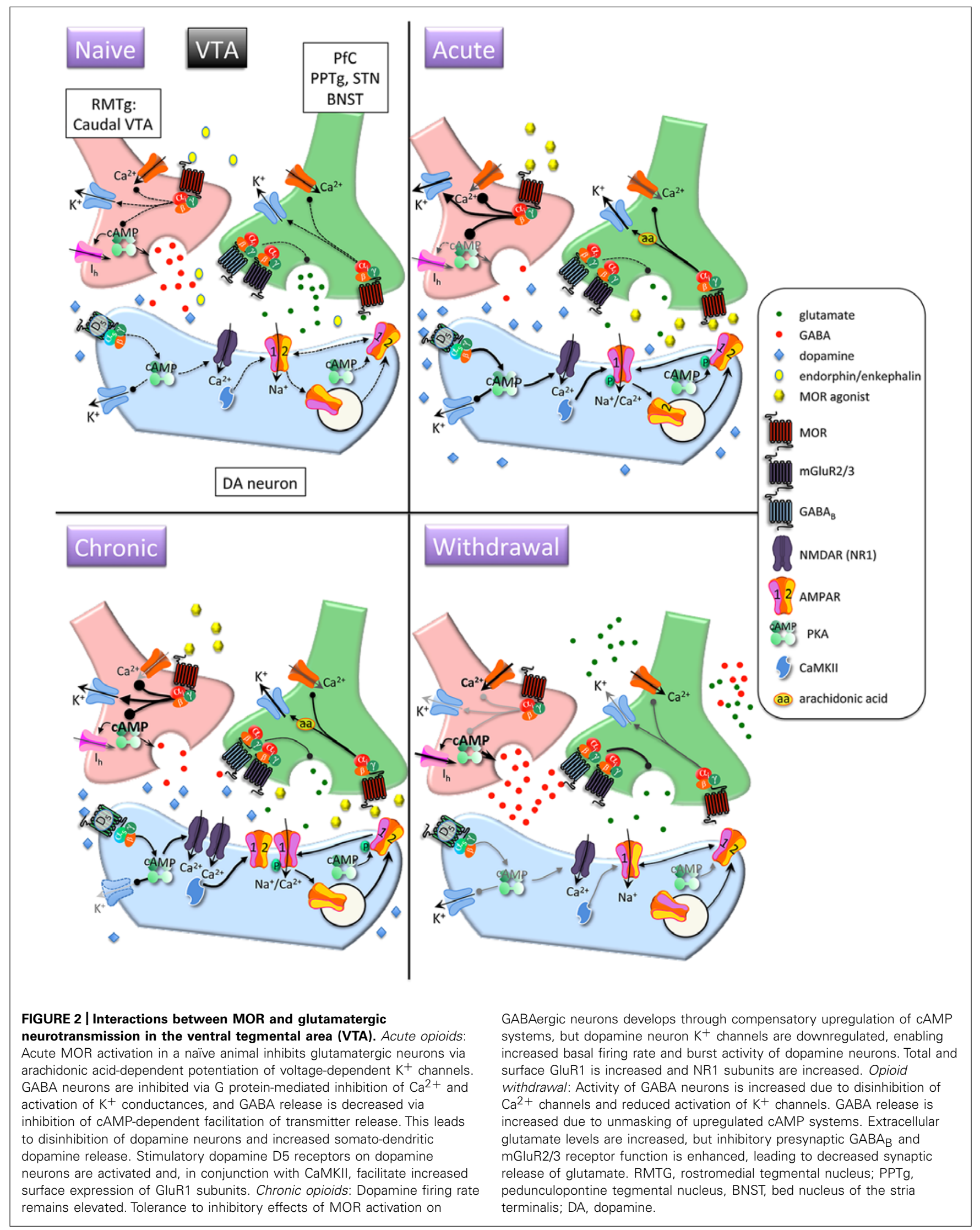




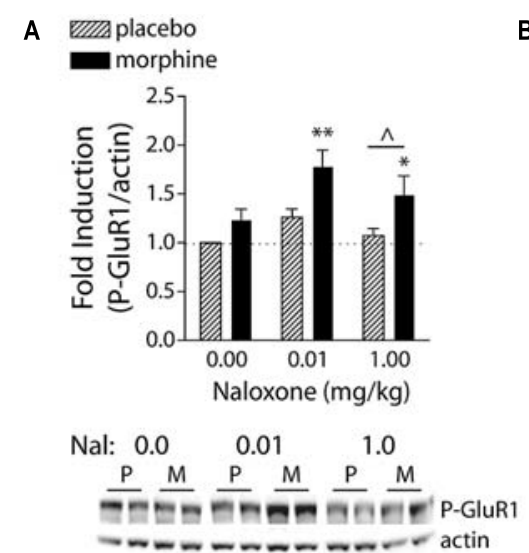

FIGURE 3 | Naloxone-precipitated morphine withdrawal increases GluR1 phosphorylation in a PKA-dependent manner. (A) Rats were subcutaneously implanted with morphine $(2 \times 75 \mathrm{mg})$ or placebo pellets and returned to their home cages for 3 days in order for morphine dependence to develop. Naloxone $(0.0,0.01$, or $1.0 \mathrm{mg} / \mathrm{kg}, \mathrm{SC})$ was injected and rats killed 30 min later. Brains were removed and frozen, $1-\mathrm{mm}^{3}$ punches of the NAc were extracted, and P-GluR1 Ser845 and $\beta$-actin (protein loading control) were quantified on immunoblots. Data are expressed as fold-induction of P-GluR1/actin levels relative to non-dependent (placebo) rats treated with vehicle. ${ }^{*} p<0.05,{ }^{*} p<0.01$ compared to non-dependent (placebo) rats treated with vehicle. ${ }^{\wedge} p<0.05$ comparing groups under bar. $N=5-9$ rats/group. Modified from Chartoff

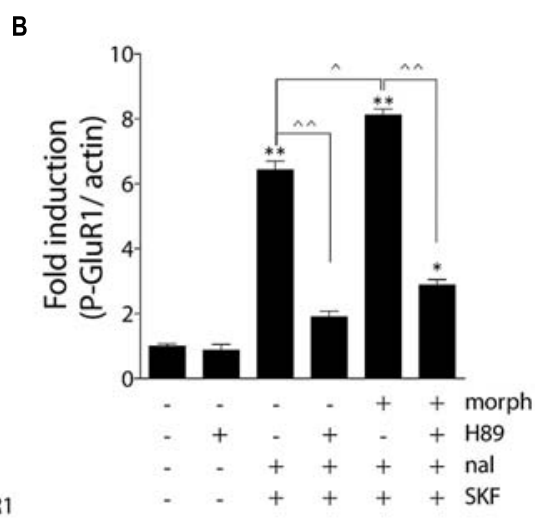

et al. (2006). (B) PKA is required for super-induction of P-GluR1 1 Ser845 during naloxone-precipitated morphine withdrawal. Primary striatal cultures were treated chronically with either vehicle or morphine (morph, $10 \mu \mathrm{M}$ ) for 6 days, followed by a 1.5-h treatment with vehicle [dimethylsulfoxide (DMSO)] or the PKA inhibitor H89 (20 $\mu \mathrm{M})$, followed by a 30-min incubation with vehicle or naloxone (nal, $10 \mu \mathrm{M})$, and the dopamine D1 receptor agonist SKF 82958 (SKF, $50 \mu \mathrm{M}$ ) for $15 \mathrm{~min}$. The ratio of P-GluR1Ser845/actin was determined for each sample and normalized to the control group ratio to yield a fold induction. Data are plotted as the mean fold induction \pm SEM. ${ }^{*} p<0.05,{ }^{* *} p<0.01$ compared with control. ${ }^{\wedge} p<0.05, \wedge \wedge p<0.01$ comparing groups designated by solid lines. $N=3$ experiments with treatments in triplicate (see Chartoff etal., 2003a for details). subunits are delivered to synapses in a precisely regulated manner and are critical for experience-dependent plasticity (see Malinow and Malenka, 2002). In the absence of activity, synapses can be devoid of GluR1-2-containing AMPARs. PKA-mediated phosphorylation of GluR1 at $\operatorname{Ser}^{845}$ (P-GluR1 ${ }^{\text {Ser845}}$ ) enhances channel conductance and open probability, and in combination with activity-dependent $\mathrm{Ca}^{2+}$ signaling (e.g. via NMDARs), phosphorylation can drive GluR1 into synapses, which could allow synaptic strengthening (Esteban et al., 2003). Importantly, P-GluR1 $1^{\text {Ser845 }}$ is necessary but not sufficient for trafficking of GluR1 subunits to synapses (e.g. Figure 2, Chronic condition). In the NAc, this type of plasticity might involve convergence of dopamine and glutamate inputs (Wolf et al., 2003): activation of postsynaptic D1 receptors induces P-GluR $1^{\text {Ser845 }}$ and activation of NMDARs could allow synaptic delivery. Conversely, activation of AMPARs can lead to compensatory dephosphorylation of GluR1 and subsequent removal from synaptic zones to intracellular vesicles (Beattie et al., 2000; Snyder et al., 2003).

Synaptic scaling is a homeostatic form of plasticity in which prolonged activity or lack of activity at AMPARs ( $\sim 1-3$ days) leads to compensatory decreases or increases, respectively, in synaptic AMPAR levels (Turrigiano, 2008). This phenomenon is thought to stabilize neuronal activity during periods of abnormal or pathological activity, and may be highly relevant to addiction and drug withdrawal.

\section{NMDA RECEPTORS}

NMDARs are a subgroup of ionotropic glutamate receptors found throughout the brain that act - in concert with colocalized
AMPARs - as synaptic coincidence detectors to facilitate learning and memory (Tang etal., 1999; Citri and Malenka, 2008). NMDARs exist as heterotetramers composed of two NR1 subunits and two subunits from the NR2 or NR3 family (Seeburg et al., 1995). NR1 subunits are expressed ubiquitously in the brain, whereas NR2 subunits are spatially localized (Dunah et al., 1999). The basal forebrain (includes the NAc) is enriched for NR2A and $B$, with a predominance of NR2B in NAc medium spiny neurons (MSNs; Chen and Reiner, 1996; Kuppenbender et al., 2000). NMDARs are unique in that they require both ligand (glutamate) binding and membrane depolarization (to release extracellular $\mathrm{Mg}^{2+}$ block) in order to be activated. Once activated, NMDARs conduct both $\mathrm{Na}^{+}$and $\mathrm{Ca}^{2+}$, which results in excitatory postsynaptic currents (EPSCs) with greater magnitude and longer half-life than those from AMPARs that pass only $\mathrm{Na}^{+}$. Perhaps most importantly, NMDAR activation engages $\mathrm{Ca}^{2+}$-mediated signal transduction pathways that can have longlasting effects on gene expression, post-translational modifications of proteins (e.g., phosphorylation), and voltage-gated ion channels (Hyman etal., 2006). In fact, $\mathrm{Ca}^{2+}$ influx is required for NMDAR-mediated long-term potentiation (LTP). The NR1 subunit is essential for channel function whereas NR2 subunits control channel gating and $\mathrm{Mg}^{2+}$ dependency (Monyer et al., 1992).

Anatomical studies have shown that MORs and NMDARs colocalize on single neurons in many brain regions, including within the dorsal striatum and NAc shell (Trujillo, 2002; Glass et al., 2009). More recently, immunoprecipitation analysis has revealed that MORs can directly interact with NMDA NR1 subunits (Rodriguez-Munoz et al., 2012). This pattern was observed in 
the PAG, cerebral cortex, striatum, and dorsal spinal cord, suggesting functional interactions between MOR and NR1 are important for analgesic and affective responses to opioids.

The importance of NMDARs to opioid dependence and the OWS may lie in the well established role of NMDARs in forming associative memories via their ability to detect two coincident synaptic events at the cellular level (i.e., LTP; long-term depression, LTD). This type of learning is thought to be important for phenomena such as conditioned craving and conditioned withdrawal, which are common in abstinent opiate addicts and are major triggers of relapse. There is also evidence that NMDARmediated plasticity is necessary for extinction of drug-associated memories. Specifically, the NMDAR partial agonist, D-cycloserine (DCS) facilitates extinction of morphine withdrawal-associated place aversions in morphine-dependent rats (Myers and Carlezon, 2010a) and extinction of cocaine-induced conditioned place preferences (Botreau et al., 2006; Paolone et al., 2009).

Although NMDARs are classically thought of as a major substrate for Hebbian learning, they can also have unconditioned effects on reward and affective states. For example, rats will selfadminister competitive and non-competitive NMDAR antagonists directly into the NAc (Carlezon and Wise, 1996b), and NMDAR antagonists potentiate brain stimulation reward (Carlezon and Wise, 1996a). These findings suggest that a reduction in the overall excitability of neurons in the NAc (via NMDAR blockade) and/or a reduction in intracellular $\mathrm{Ca}^{2+}$ signaling is sufficient for reward. It is likely that NMDAR-mediated increases in synaptic strength (learning) and changes in affective state are not mutually exclusive processes. One can envision a scenario during drug withdrawal in which the experience of an intense dysphoric state is stamped into memory through NMDAR activation in select brain regions. This idea will be discussed in more detail in the following sections.

\section{NUCLEUS ACCUMBENS}

The NAc (ventral striatum) can be subdivided into multiple territories based on functional connectivity and neuronal phenotypes (Zahm and Brog, 1992). The NAc core is a central portion of the ventral striatum that surrounds the anterior commissure and is a functional continuation of the neighboring dorsal striatum. It has been shown to be particularly important for instrumental learning such as cue-induced reinstatement of drug seeking (McFarland and Kalivas, 2001). The shell comprises the most ventral and medial portions of the NAc, and has an important role in drug reward, motivated behavior, behavioral sensitization, and changes in affective state. In addition, subterritories such as the rostral pole, cone and intermediate zone of the NAc shell have been described (Zahm and Brog, 1992). A longstanding conception is that the NAc is a "motivation to movement interface" (Mogenson et al., 1980), and accumulating evidence has confirmed this idea by identifying the neural circuits that loop from limbic and cognitive cortical regions to motor output regions (Haber and Knutson, 2010). Thus, the NAc is a key site for transference of motivational and emotional signals to adaptive behavioral responses. Despite its long tenure as the "reward center" of the brain, increasing evidence supports the idea that the NAc is a bivalent structure that processes positive and negative emotional stimuli into either approach or avoidance behavior (Becerra et al., 2001; Reynolds and Berridge, 2002; Jensen et al., 2003; Roitman etal., 2005; Carlezon and Thomas, 2009). This has important ramifications for understanding addiction, since drugs of abuse provide hyperbolic positive (drug "high") and negative (drug withdrawal, "crash") emotional signals to the NAc.

\section{AFFERENTS}

Consistent with the view that the NAc gates rewarding and aversive stimuli and directs subsequent goal-directed behavior, NAc afferents come from brain regions known to be important for processing both positive and negative emotional stimuli, such as the basolateral amygdala (Kelley et al., 1982) and for goal-directed behavior, including the orbitofrontal cortex, insula, cingulate cortex (Berendse et al., 1992), and midline and intra-laminar thalamic nuclei (Berendse and Groenewegen, 1990). In addition, the NAc receives rich innervation from the ventral subiculum of the hippocampus (Kelley and Domesick, 1982; Groenewegen et al., 1987), which likely provides spatial and contextual information about the stimuli (for review of NAc afferents, see Brog et al., 1993; Sesack and Grace, 2010). The vast majority of NAc afferents are glutamatergic and provide the excitatory drive necessary to evoke behavior. The NAc also receives some inhibitory, GABAergic inputs from the ventral pallidum and the VTA, as well as local inhibitory connections from within the striatum (Brog et al., 1993; Sesack and Grace, 2010). Layered on top of fast neurotransmission controlled by glutamate and GABA, the output of the NAc is modulated by robust networks of neuropeptides, both intrinsic and extrinsic to the NAc. These include, but are not limited to, orexin, dynorphin, enkephalin, substance $\mathrm{P}$, and neurotensin (Hokfelt et al., 2000). Finally, dopamine afferents from the VTA provide an essential component of reward processing in the NAc. Dopamine modulates the general excitability of NAc neurons, thus increasing or decreasing behavioral output based on the level of emotional salience coded by the dopamine input (Koob, 1992; Ikemoto and Panksepp, 1999; Wise, 2004).

\section{INTRINSIC SIGNALING}

Within the NAc, GABA-containing medium spiny output neurons comprise the majority ( $\sim 90-95 \%$ ) of neurons (Wilson and Groves, 1980; Gerfen, 1992), with the remaining cells being either GABAergic or cholinergic interneurons (Kawaguchi et al., 1995). The function of MSNs depends on their particular inputs and outputs, but also on the phenotype of the MSN itself. Only recently have researchers had the tools to begin to dissect the complex microcircuitry of the NAc. As with the dorsal striatum, NAc MSNs can be broadly divided into dopamine $\mathrm{D}_{1}$-like (includes $\mathrm{D}_{1}$ and $\mathrm{D}_{5}$ receptors) or dopamine $\mathrm{D}_{2}$-like (includes $\mathrm{D}_{2}, \mathrm{D}_{3}$, and $\mathrm{D}_{4}$ ) receptor expressing circuits (Gerfen et al., 1990; Lobo, 2009). MSNs express different constellations of neuropeptides, with dynorphin often co-expressing with dopamine $\mathrm{D}_{1}$ receptors and enkephalin with dopamine $\mathrm{D}_{2}$ receptors (Gerfen et al., 1990; Lobo, 2009). In the NAc, MORs are expressed primarily by dynorphin- and $D_{1}$ receptor-expressing cells (Georges et al., 1999).

Glutamate neurotransmission is kept under tight control: too much or too little can have devastating effects (Kalivas, 
2009), whereas stimulus-dependent changes in glutamatergic transmission are necessary for learning (Kauer and Malenka, 2007). Structurally, synaptic input to MSNs is arranged such that glutamatergic afferents synapse on dendritic spines and modulatory inputs such as dopamine make connections extrasynaptically on dendritic shafts. This triad of spine, glutamate synapse and dopamine synapse allows dopamine to modulate the general excitability of NAc neurons (Surmeier etal., 2007; Sesack and Grace, 2010). Glutamatergic activation of NAc MSNs is mediated primarily by AMPARs (Hu and White, 1996). Approximately $90 \%$ of AMPARs in the NAc are made of GluR1 and GluR2 or GluR3 containing tetramers with only about 6\% being GluR1-3 complexes (Wolf, 2010; Reimers et al., 2011). There is some evidence for a very small percentage of AMPARs in the NAc to exist as GluR1 homomers. Functionally, this implies that the vast majority of NAc AMPARs conduct $\mathrm{Na}^{+}$but not $\mathrm{Ca}^{2+}$, given that GluR2 renders AMPARs impermeable to $\mathrm{Ca}^{2+}$. NMDARs play a critical role in tagging connections that receive convergent glutamate and dopamine inputs. For example, cortical excitation of selected MSNs in the presence of dopamine would lead to an increase in synaptic strength in a two-step process: activation of postsynaptic $\mathrm{D}_{1}$ receptors induces PKA-dependent P-GluR1 ${ }^{\text {Ser845 }}$ and activation of NMDARs facilitates synaptic delivery of GluR1 (Wolf, 2010).

\section{EFFERENTS}

The functional consequences of glutamate transmission in the NAc are being elucidated: in general, NAc neurons are activated in response to aversive stimuli and inhibited in response to rewarding stimuli (Peoples and West, 1996; Carelli, 2002; Roitman et al., 2005). GABAergic MSNs from the NAc project to the ventral pallidum, substantia nigra (SN), VTA, hypothalamus, and brainstem (Haber et al., 1990). There is topographical organization such that a medial (i.e., shell) to lateral (i.e., core/dorsal striatum) series of projection loops allows emotion-based information from limbicassociated structures to transfer to motor-related areas of the basal ganglia (Haber et al., 2000). Within these spiraling loops, some NAc outputs - particularly in the core - are functionally analogous to the direct and indirect pathways described for the dorsal striatum (Sesack and Grace, 2010). Activation of $\mathrm{G}_{\alpha \mathrm{s}}$-coupled $\mathrm{D}_{1}$ like receptors stimulates production of cAMP and tends to excite MSNs that project directly back to the VTA and the ventral pallidum (direct pathway), whereas activation of $\mathrm{G}_{\alpha \mathrm{i}}$-coupled $\mathrm{D}_{2}$-like receptors inhibits cAMP production and tends to inhibit MSNs that selectively project to the ventral pallidum (indirect pathway; Lu et al., 1998; Surmeier et al., 2007). Thus, cortical activation of the direct pathway leads to disinhibition of motor circuits that enable reward acquisition whereas activation of the indirect pathway inhibits motor circuits that are maladaptive (Mink, 1996).

\section{VENTRAL TEGMENTAL AREA}

The VTA has been extensively studied for its role in reward and addiction. Opioids are self-administered directly into the VTA (Bozarth and Wise, 1981; Devine and Wise, 1994), while blockade of VTA MORs suppresses heroin self-administration (Britt and
Wise, 1983). Intra-VTA morphine injections produce conditioned place preferences (Bozarth, 1987), enhance the rewarding impact of intracranial self-stimulation (Broekkamp et al., 1976), and reinstate extinguished lever pressing for heroin (Stewart et al., 1984). Dopamine neurons make up about $60-65 \%$ of the cells in the VTA, with GABAergic ( $25 \%$ ) and glutamatergic (up to 15\%) neurons making up the rest (Swanson, 1982; Nair-Roberts et al., 2008). Most classes of drugs of abuse increase dopamine release in efferent targets of the VTA, including the NAc (Di Chiara and Imperato, 1988a). Comprehensive reviews of the role of VTA dopamine in reward function and addiction have been published (Berridge and Robinson, 1998; Wise, 2004; Fields et al., 2007; Ikemoto, 2007; Wheeler and Carelli, 2009; Salamone and Correa, 2012), with the emerging view that not only does dopamine mediate the positive reinforcing effects of drugs but it is also instrumental in learning how particular behaviors lead to reward or aversion (Volman et al., 2013).

\section{AFFERENTS}

The VTA is regulated by an integrated network of excitatory inputs arising from the PFC, the pedunculopontine region (PPTg), the laterodorsal tegmentum (LDTg), and the sub thalamic nucleus (Grace et al., 2007). These connections are organized in the sense that glutamatergic inputs from the medial PFC (mPFC) synapse on dopamine neurons that project back to the mPFC but not on those that project to the NAc (Carr and Sesack, 2000). The VTA and the more caudal "tail" of the VTA (RMTg) receives GABAergic input from the lateral habenula, NAc shell, and ventral pallidum (Zahm and Heimer, 1990; Jhou et al., 2009). Importantly, the RMTg provides tonic GABAergic inhibition of VTA dopamine neurons that keeps them in a pacemaker-type firing pattern in the absence of stimulation (Bourdy and Barrot, 2012). The transition from pacemaker-like firing of dopamine neurons to burst firing, which is thought to represent a phasic dopamine response associated with reward and reward-related cues, requires glutamate input from the PPTg-LDT complex (Floresco et al., 2003; Lodge and Grace, 2006; Grace et al., 2007).

\section{INTRINSIC SIGNALING}

GABA neurons of the VTA and RMTg express dense MOR mRNA and immunoreactivity (Mansour et al., 1988, 1995a; Garzon and Pickel, 2001; Svingos et al., 2001; Jhou et al., 2009). Morphine indirectly excites dopamine neurons via inhibition of these GABA neurons that synapse on dopaminergic dendrites in the VTA (Johnson and North, 1992; Jalabert et al., 2011). This disinhibition of dopamine neurons requires NMDAR and AMPAR activation (Jalabert et al., 2011). Taken together, the effects of opioids on VTA function involve a close interaction between postsynaptic MORs and glutamate signaling.

\section{EFFERENTS}

There is a topographical organization to the VTA, with dopamine and GABAergic efferents having a medial to lateral projection to output structures such as the NAc, PFC, cingulate cortex, and basolateral amygdala (Ikemoto, 2007). In addition, there is a rostral to caudal organization in which the ratio of dopamine to GABA decreases caudally (Bourdy and Barrot, 2012). In broad terms, 
there are stronger drug reward associations in the caudal-medial versus anterior VTA (Ikemoto, 2007).

\section{ACUTE OPIOIDS CLINICAL DESCRIPTION}

The National Survey on Drug Use and Health (NSDUH, 2013), the National Monitoring the Future survey study (Johnston et al., 2014), and the Columbia CASA report (The National Center on Addiction and Substance Abuse, Columbia University, 2011) provide consistently alarming trends of early age initiation of prescription opioid misuse (1.5\% of children age $12-13$ years old used in the prior month) and heroin use, with a national average age of opioid initiation between 22 and 23 years old. Teenagers report high availability of illicit opioids: 20 and $45 \%$ of high school seniors report it is easy to get heroin and prescription opioids, respectively (Johnston et al., 2014). Teens report using both to get high and to relieve tension, despite pervasive disapproval and perceived risk (The National Center on Addiction and Substance Abuse, Columbia University, 2011). Teens describe being high on opioids as, "the best feeling ever," or, "I finally felt happy," which is not different from the self-reported experiences of adult initiates.

\section{MOR-GLUTAMATE INTERACTIONS IN THE NAc (see Figure 1)}

Acute administration of opioids activates MORs and increases extracellular dopamine in the NAc (Figure 1, yellow ovals; Di Chiara and Imperato, 1988a). However, dopamine is not necessary for the acute rewarding effects of opiates in non-dependent animals, as dopamine receptor blockade or 6-hydroxydopamine (6-OHDA)-mediated dopamine denervation of the NAc does not prevent heroin self-administration (Pettit et al., 1984; Gerrits and Van Ree, 1996). Even evidence demonstrating a requirement for the NAc in opiate reward and reinforcement is equivocal. For example, mice can learn to self-administer MOR agonists directly into the NAc (Goeders etal., 1984; David and Cazala, 2000), and yet intra-NAc morphine fails to produce conditioned place preferences in rats (Schildein et al., 1998). Lesions or inactivation of the NAc partially reduce opiate self-administration (Zito et al., 1985; Dworkin et al., 1988; Alderson et al., 2001), but it is difficult to interpret the meaning of these data on their own, since a decrease in the number of drug infusions at a single drug dose can mean either a decrease or an increase in the reinforcing efficacy of a drug (Mello and Negus, 1996). A study showing that NAc lesions reduced progressive ratio (PR) responding for morphine in rats (Suto et al., 2011) supports the idea that the NAc plays a role in the motivation to work for morphine. Yet direct infusions of MOR antagonists into the NAc actually increase heroin self-administration (Vaccarino et al., 1985), which the authors interpret as a decrease in the reinforcing efficacy of heroin driving increased drug-taking. Thus, the NAc can modulate opioid reward and drug-taking behavior, but its precise role is complicated by prior drug experience and method of administration.

Human imaging studies have generally shown that, in drugexperienced people, an immediate (i.e., during the "rush") effect of opioid administration is an increase in regional cerebral blood flow in the anterior cingulate cortex, thalamus, and amygdala
(Schlaepfer et al., 1998; Kosel et al., 2008). In contrast, after the initial "rush" has subsided and the longer lasting euphoric effects of acute opioids emerge, blood flow tends to be decreased (London et al., 1990; Denier et al., 2013). This is consistent with electrophysiological and neurochemical findings in rats, in which systemic morphine inhibits spontaneous firing of a majority of neurons in the mPFC (Giacchino and Henriksen, 1996). In many neurons, MOR-mediated inhibition of adenylate cyclase results in a decrease in cAMP-dependent activation of voltage-dependent $I_{\mathrm{h}}$ pacemaker currents (Figure 1, GABAergic neurons, Acute condition; Williams et al., 2001). A decrease in cAMP shifts the voltage dependence to more negative potentials, making it harder to depolarize the neuron. MOR activation suppresses basal and evoked increases in extracellular glutamate in the NAc and dorsal striatum (Figure 1, glutamate neurons, Acute and Chronic conditions; Desole et al., 1996; Enrico et al., 1998; Sepulveda et al., 2004). Although the functional consequences of changes in cerebral blood flow and cortical activation are not yet known, the findings suggest that opioid-induced reward is associated with decreased cortical activity and potentially decreased glutamatergic input to downstream NAc MSNs. Despite the evidence for opiate modulation of glutamate release in the NAc, there is relatively little data on the role AMPAR and NMDAR play in mediating the acute rewarding effects of opiates. This is surprising, given the previously discussed findings that acute opiates have profound effects on glutamatergic projections to the NAc and that the activation state of MSNs plays an important role in affect and emotional responses to stimuli (Roitman et al., 2005; Carlezon and Thomas, 2009). One prediction, based on synaptic scaling (Turrigiano, 2008), is that opiate-induced decreases in glutamatergic transmission to the NAc would result in increased surface expression of AMPARs. There are no known studies that address this prediction directly. Rather, there is evidence that expression of NMDAR and AMPAR subunits is decreased in the NAc core 3 days after acute morphine exposure (Jacobs et al., 2005). Similarly, there is one study that reports a decrease in surface levels of NAc GluR1 $24 \mathrm{~h}$ after an acute morphine injection (Herrold et al., 2013). Unfortunately this time course does not actually reflect the acute rewarding effects of morphine but may rather reflect a state of acute withdrawal (Rothwell etal., 2012).

Using intracellular recordings from NAc slice preparations, it has been reported that acute MOR activation depresses NMDA and non-NMDA (presumably AMPA) excitatory postsynaptic potentials (EPSPs) in the NAc through a presynaptic mechanism involving reductions in spike-generated $\mathrm{Ca}^{2+}$ currents (Martin et al., 1997). A general effect of MOR activation that could account for this is inhibition of presynaptic voltage-gated $\mathrm{Ca}^{2+}$ channels (L-, N-, P/Q-, R-) through $\mathrm{G}_{\alpha \alpha_{0}}-\beta \gamma$ subunits (see Figures 1 and 2, presynaptic glutamatergic neuron, Acute condition; Law et al., 2000). Although this would predict a decrease in MSN activation, this study also demonstrated that postsynaptic NMDA currents were augmented via a protein kinase $\mathrm{C}$ (PKC)-dependent mechanism (Figure 1, postsynaptic GABA neuron, Acute condition). The ultimate consequences of these opposing MOR actions are still not fully understood. A more recent study in awake and behaving rats showed that a non-contingent injection of heroin produced a small 
decrease (not significant) in extracellular glutamate in the core in drug-naïve rats (LaLumiere and Kalivas, 2008). Taken together, the available data suggest that acute opiates decrease glutamate release in the NAc in non-dependent animals, which is consistent with the general finding that decreases in NAc MSN activation are associated with reward-like states (Carlezon and Thomas, 2009).

\section{MOR-GLUTAMATE INTERACTIONS IN THE VTA (see Figure 2)}

An immediate effect of an acute opiate injection is inhibition of MOR-containing GABAergic neurons (Figure 2, GABAergic neuron, Acute condition) in the RMTg that make strong synaptic contacts on the soma and dendrites of dopamine neurons and a subsequent decrease in LTP of these GABAergic synapses (Johnson and North, 1992; Niehaus et al., 2010; Jalabert et al., 2011; Mazei-Robison et al., 2011). A second immediate effect is a presynaptic inhibition of glutamatergic afferents via MOR-mediated, arachidonic acid-dependent, activation of voltage-sensitive $\mathrm{K}^{+}$ channels (Figure 2, Glutamate neuron, Acute condition; Manzoni and Williams, 1999). This effect on glutamate release is confusing, because one would expect morphine to produce rapid activation of dopamine neurons through both inhibition of GABA inputs and excitation of glutamatergic inputs. In fact, it has been reported that an opiate-dependent increase in AMPAR activation in the VTA is required for disinhibition of dopamine neurons (Gysling and Wang, 1983; Di Chiara and Imperato, 1988a; Jalabert et al., 2011). Although not fully understood, the issue is likely related to timing.

An acute response common to most classes of drugs of abuse, including opiates, is an increase in AMPA transmission in dopamine neurons measured $24 \mathrm{~h}$ after acute administration of drug (Ungless et al., 2001; Saal et al., 2003; Brown et al., 2010). This is thought to be due to an increase in surface expression of AMPARs. Since acute morphine inhibits activity of glutamatergic afferent neurons (Giacchino and Henriksen, 1996; Manzoni and Williams, 1999), this observed increase in evoked AMPA transmission may not immediately translate to increased excitation of the VTA. Rather, morphine-induced decreases in glutamate release to the VTA may promote compensatory, postsynaptic increases in AMPA signaling that produce LTP at select synapses. Consistent with this, an increase in surface expression of GluR1 in the VTA (Figure 2, Dopamine neuron, Acute condition) has been reported $24 \mathrm{~h}$ (Brown et al., 2010), and as early as $1 \mathrm{~h}$ (Lane et al., 2008), after morphine injection. The mechanism through which morphine increases GluR1 synaptic insertion and LTP is not fully understood, but is thought to involve stimulation of dopamine $\mathrm{D}_{5}$ receptors (Figure 2, Dopamine neuron, Acute condition), which belong to the Gas-coupled D1-like receptor family (Schilstrom et al., 2006; Brown et al., 2010). $D_{5}$, unlike $\mathrm{D}_{1}$, receptors are expressed on dopamine neurons of the VTA (Weiner et al., 1991; Khan et al., 2000). Thus, morphineinduced dopamine release can stimulate $\mathrm{D}_{5}$ receptors in the VTA, which would activate cAMP-dependent processes including PKA-dependent phosphorylation of GluR1. Phosphorylation of GluR1 facilitates synaptic insertion and increases synaptic current (Kessels and Malinow, 2009), providing a potential mechanism for feed-forward enhancement of morphine's actions on dopamine neurons. Consistent with this, overexpressing GluR1 AMPAR subunits in the VTA sensitizes rats to the locomotor effects of acute morphine and potentiates morphine-induced conditioned place preferences (Carlezon et al., 1997). Although GluR1 trafficking is evident after only one injection of morphine, it is thought that the cumulative effects of repeated morphine treatment are necessary for the plasticity in dopamine neuron excitability that contribute to the development of sensitization (Carlezon and Nestler, 2002).

A critical role for VTA AMPA and NMDARs in acute opiate reward has been demonstrated in behavioral studies. Intra-VTA delivery of an NMDAR or an AMPAR antagonist increased heroin self-administration in the same manner that decreasing the available dose of heroin does (Xi and Stein, 2002). This is consistent with the idea that NMDA and AMPAR activation is necessary for the acute reinforcing effects of opioids. Intra-VTA blockade of either NMDAR or AMPAR decreases both the acquisition and expression of morphine conditioned place preferences (Harris et al., 2004). Place conditioning depends upon an associative memory of the pairing of an affective state (reward or aversion) with a context. Thus, the role of VTA glutamate transmission in opiate effects could be to promote associative learning and/or to promote a rewarding state that has salience as an unconditioned stimulus in the place conditioning paradigm.

\section{CHRONIC OPIOIDS CLINICAL DESCRIPTION}

Most individuals who are recently opioid-dependent are not fully aware they are "hooked." Getting high is still euphoric, and mild withdrawal symptoms are surprising and manageable. Cognitive appraisal is, "I can stop if I need to." Seeking a more intensive high may lead the individual to change to a route of administration that produces a more rapid and potent effect (e.g. oral to intranasal, or intranasal to intravenous), to try a more potent formulation (switching analgesics or getting a "good batch" of heroin), or to mixing opioid use with other substances, particularly sedativehypnotics.

Opioids can be administered chronically in a number of ways (steady dosing of extended release painkillers, repeated intermittent abuse, binge-type self-administration, or any combination of the preceding), which likely influences the resulting neural adaptations. As discussed above, an additional consideration in interpreting data from chronic drug studies is the time point at which molecular or behavioral measures are taken. Effects observed $24 \mathrm{~h}$ or more after the end of a chronic drug regimen may more accurately reflect drug withdrawal rather than chronic effects per se. Furthermore, accumulating evidence suggests that GPCRs (e.g., MOR) modulate synaptic activity on a timescale that extends well beyond that of initial receptor activation, resulting in a metaplasticity that can either lower or raise the threshold for induction of LTP-like processes (Tenorio et al., 2010).

\section{MOR-GLUTAMATE INTERACTIONS IN THE NAC}

Chronic activation of MORs triggers counteradaptions in cAMP signaling such that adenylate cyclase function is enhanced (Nestler and Aghajanian, 1997; Williams etal., 2001). The presence of 
chronic opioids masks the effects of increased cAMP, but it alters how other GPCRs signal through adenylate cyclase. As one example, chronic morphine increases the inhibitory efficacy of presynaptic mGluR2/3 receptors on glutamate release in the NAc (Figure 1, Glutamatergic neuron, Chronic condition; Martin etal., 1999). This may evolve from an increased functional connectivity between $\mathrm{mGluR} 2 / 3$ receptors and upregulated cAMP signaling.

Numerous studies have examined effects of repeated psychostimulants (contingent and non-contingent administration protocols) on AMPAR-mediated synaptic transmission in the NAc (Wolf et al., 2004; Luscher, 2013; Pierce and Wolf, 2013). Unfortunately, relatively little is known about effects of chronic opioids. These types of studies are important, because available research has shown that cellular and structural consequences of opioids often differ from those of psychostimulants (Badiani et al., 2011). Chronic, steady state levels of morphine achieved with subcutaneous morphine pellet implants do not change total protein levels of AMPAR subunits (Chartoff et al., 2006), although this does not take into account changes in subcellular localization. To address this, Glass et al. (2008) used immunogold ultrastructural analysis to demonstrate that surface expression of GluR1 subunits is decreased after chronic morphine treatment ( $1 \mathrm{~h}$ after 14 days of non-contingent injections; Figure 1, postsynaptic GABA neuron, Chronic condition). This effect was localized to dopamine D1 receptor-expressing neurons in the NAc shell and in all MSN types in the core. In contrast, a different opiate regimen ( 1 day after 1 injection/day for 3 days) produced no change in subcellular distribution of either GluR1 or 2 in the NAc (Mickiewicz and Napier, 2011). The mechanisms by which chronic opioids modulate subcellular distribution of AMPAR subunits are not known. However, given that activation of MORs inhibits adenylate cyclase and CAMP production, it is possible that the resulting brake on PKA function leads to decreased P-GluR1 $1^{\text {Ser845 }}$ in the NAc (Figure 1, postsynaptic GABA neuron, Chronic condition), which would favor internalization processes (Song and Huganir, 2002; Mangiavacchi and Wolf, 2004). This is consistent with formation of LTD, which requires clathrin-dependent endocytosis of postsynaptic AMPARs (Brebner et al., 2005).

More is known about the effects of chronic morphine on NMDAR-mediated synaptic transmission in the NAc compared to AMPA transmission. As discussed above, acute morphine's actions in the NAc include presynaptic inhibition of glutamate release as well as a postsynaptic potentiation of NMDAR EPSPs via activation of PKC (Martin et al., 1997). Postsynaptically, chronic morphine appears to have several effects on NMDARs, including a decrease in affinity for the co-agonist glycine and a decrease in the sensitivity of PKC-mediated NMDAR activation. Using dissociated primary cultures of NAc neurons, it was shown that these effects may be due, in part, to an increase in expression or function of the NR2A subunit (Figure 1, postsynaptic GABA neuron, Chronic condition; Martin etal., 2004). In vivo studies have reported increased protein levels of NR1 and NR2A in the NAc after chronic morphine (Inoue et al., 2003; Murray et al., 2007), although a separate study did not detect a change in NR2A (Bajo et al., 2006). An intriguing possibility for how MORs and NMDARs interact is described in the opioid pain literature. It has been reported that MORs and NR1 subunits physically associate in the periaqueductal gray (Rodriguez-Munoz et al., 2012). Although it is not known if this occurs in the NAc or VTA, it raises the possibility that MORs can have direct effects on glutamate signaling through $\mathrm{G}$ protein signaling and/or through direct interaction.

\section{MOR-GLUTAMATE INTERACTIONS IN THE VTA}

Both basal firing rate and burst activity of VTA dopamine neurons are increased after acute, and during chronic, morphine treatment, resulting in elevated tonic levels of dopamine in the NAc (Leri et al., 2003; Georges et al., 2006; although see MazeiRobison etal., 2011). However, an acute morphine challenge fails to further increase dopamine neuron activity (Georges et al., 2006), suggesting tolerance at the level of dopamine neuron activation. Recently it has been shown that chronic morphine increases intrinsic excitability of VTA dopamine neurons through downregulation of $\mathrm{K}^{+}$channels (Figure 2, Dopamine neuron, Chronic condition) concomitantly with decreases in dopamine soma size (Mazei-Robison et al., 2011). Thus, dopamine neurons are more likely to fire, but because of their smaller size they release less dopamine. Taken together, these data raise the possibility that not only does chronic morphine maintain its inhibitory influence on GABAergic neurons in the VTA and RMTg, but it also increases the sensitivity of dopamine neurons to excitation (via $I_{\mathrm{h}}$ ). Chronic morphine increases total levels of GluR1 and NMDA NR1 subunits in the VTA (Fitzgerald et al., 1996), and ultrastructural analysis showed that surface GluR1 is increased in dopaminergic and non-dopaminergic neurons of the parabrachial and paranigral VTA (Figure 2, Dopamine neuron, Chronic condition; Lane et al., 2008). These findings could explain, at least in part, how postsynaptic glutamate transmission is augmented with chronic opioid treatment, and they also demonstrate that normal glutamatergic signaling is fundamentally altered. In the presence of morphine, arachidonic acid-dependent activation of voltage-dependent $\mathrm{K}^{+}$conductances continues to reduce glutamate release from afferent terminals (Manzoni and Williams, 1999). Yet signaling through GluR1 and possibly NR1 subunits on postsynaptic cells is enhanced (LTP-like; Fitzgerald etal., 1996; Lane etal., 2008), with no evidence so far of changes in other AMPAR or NMDAR subunits.

The effects of these seemingly opposite phenomena on behavior are not well understood, and provide an important area of future investigation. Given that AMPARs lacking GluR2 subunits and NMDARs are able to pass $\mathrm{Ca}^{2+}$, the increase in VTA GluR1 and NR1 likely results in increased $\mathrm{Ca}^{2+}$-mediated signaling (Figure 2, Dopamine neuron, Chronic condition), which would be expected to selectively strengthen those synaptic connections that express elevated GluR1 and NR1. Consistent with this, intra-VTA infusion of NMDAR or AMPAR antagonists prior to morphine conditioning sessions or prior to tests for morphine conditioned place preferences blocked the development and expression, respectively, of place preferences (Popik and Kolasiewicz, 1999; Harris et al., 2004). These effects appear to be limited to the rostral VTA (enriched for dopamine neurons), as AMPAR blockade of the caudal VTA (enriched for GABA neurons) had no effect on morphine 
conditioned place preferences (Shabat-Simon et al., 2008). Also, mice with a global knockout of GluR1 show reduced naloxoneprecipitated withdrawal signs after an escalating dose regimen of morphine (Vekovischeva et al., 2001). This suggests that GluR1 is required for full dependence to develop. Consistent with the idea that increased GluR1 expression in the VTA facilitates dopamine neuron activation, it was shown that transient over-expression of GluR1 using HSV (herpes simplex virus) vectors in the rostral VTA increased the rewarding effects of a morphine challenge, whereas GluR overexpression in the caudal VTA had the opposite effect (Carlezon et al., 2000).

\section{OPIOID WITHDRAWAL CLINICAL DESCRIPTION}

With severe OUD, episodes of opioid withdrawal are more frequent and more aversive, and getting high gives only brief pleasure, mostly attributed to cessation of withdrawal. Individuals now use "to feel normal" and "to be able to function." Pre-occupation with obtaining a steady source of opioids is now prevalent, and episodes of anxiety, irritability, and dysphoria are more frequent. This is a stage of securing a steady opioid supply through friends, dealers, or a doctor. This is also the stage when an individual who never intended to use intravenously converts to injection use.

Forced abstinence is accompanied by severe withdrawal, anxiety, dysphoria, and intense, recurrent cravings to use opioids. Those who cannot access a source become quite desperate to obtain opioids, and will frequently self-injure in order to receive opioid analgesia in emergency health care settings. The fear of being cut off from opioid supply becomes ever-present and motivation to hoard opioid supplies becomes habitual. This may present as routinely exploring medicine cabinets while visiting friends and family, and finding reasons to visit someone during illness or post-surgical recovery, in hope of surreptitiously taking narcotic analgesics from them. This may also be a time of criminal behavior initiation (stealing, prostitution, running goods, etc.) to support an opioid habit.

Withdrawal from chronic opioids essentially unmasks all the neural adaptations the brain produced in its attempts to equilibrate in the presence of drug. Consequently, neural circuits regulating everything from gastrointestinal function to affective states are instantly unbalanced, and an OWS emerges. A primary cause of psychological withdrawal signs, which include anxiety, dysphoria, depression, and irritability, is thought to be the dramatic reduction in dopamine neuron firing and dopamine release in efferent targets (Diana et al., 1995). Neural circuits other than the mesocorticolimbic system also play critical roles in the OWS - both somatic and psychological. These include norepinephrine (NE; Weinshenker and Schroeder, 2007), corticotropin releasing factor (CRF; Contarino and Papaleo, 2005), orexin (Mahler et al., 2012), dynorphin (Yuferov et al., 2004; Schlosburg et al., 2013), and many more (for review, see Koob, 2009). It is likely that MOR-induced neuroplasticity in glutamate transmission underlies - at least in part - the effects of each of these systems on OWS.

\section{MOR-GLUTAMATE INTERACTIONS IN THE NAC}

Spontaneous or naloxone-precipitated withdrawal from chronic opioids leads to a general increase in neuronal activity and transmitter release due to the removal of inhibitory MOR tone. For example, GABA release is increased in the NAc during withdrawal, particularly after activation of adenylate cyclase (Figure 1, presynaptic GABA neuron, Withdrawal condition; Chieng and Williams, 1998). Importantly, the ability of opioids to inhibit GABA release is also enhanced, suggesting that this may be one mechanism underlying the irresistible temptation to fight OWS with opioids themselves. Glutamate release has also been shown to increase, and numerous studies have shown that systemic or intracerebroventricular administration of NMDAR or AMPAR antagonists reduces morphine tolerance and/or withdrawal signs (Trujillo and Akil, 1991; Tokuyama et al., 1996; Gonzalez et al., 1997). Much less is known about the specific role of NAc glutamate transmission in the OWS. Extracellular glutamate levels are significantly increased in the NAc during morphine withdrawal (Figure 1, presynaptic Glutamatergic neuron, Withdrawal condition; Aghajanian etal., 1994; Desole etal., 1996; Sepulveda et al., 1998, 2004), although increased extracellular glutamate does not necessarily mean that excitatory synaptic transmission is increased (Kalivas, 2009). For example, it has been shown that presynaptic mGluR2/3 inhibitory autoreceptor function is increased during morphine withdrawal (Figure 1, presynaptic Glutamatergic neuron, Withdrawal condition) and mGluR2/3 receptor agonists attenuate behavioral signs of morphine withdrawal (Robbe et al., 2002b) and context-induced reinstatement of heroin seeking (Bossert et al., 2006). These findings support the idea that, although glutamate levels are increased, synaptic transmission may be decreased during withdrawal. Thus, it is not yet clear how the combination of chronic morphineinduced increases in AMPAR and NMDAR subunit expression, withdrawal-induced increases in extracellular glutamate, and increased autoinhibition of cortical afferents is synthesized into behavioral output.

Understanding the molecular mechanisms by which increased extracellular glutamate and AMPAR and NMDAR in the NAc contribute to OWS will be key to understanding and preventing relapse. As one example, the mechanism by which presynaptic mGluR2/3 receptor function is augmented is not known. Under normal conditions, these Gai-coupled receptors inhibit evoked glutamate release by $\mathrm{P} / \mathrm{Q} \mathrm{Ca}^{2+}$ channel inhibition and PKAdependent mechanisms (Robbe et al., 2002a). Chronic morphine and withdrawal has no effect on these processes in the NAc, raising the possibility of MOR-induced novel signaling mechanisms (Robbe et al., 2002b). In a second example, Shen et al. (2011) showed that 2 weeks of extinction following 2 weeks of daily heroin self-administration resulted in thinner dendritic spines in the NAc concomitant with an increase in surface expression of NR2B subunits (Figure 1, postsynaptic GABA neuron, Withdrawal condition). Consequently, overall synaptic strength was unchanged, but the AMPA/NMDA ratio (a proxy for synaptic plasticity) was decreased due to increased NMDA current with no change in AMPA current. What this means for the OWS was not investigated in this study, but Shen et al. (2011) found that the heroin withdrawal-induced increase in surface NR2B was necessary for heroin- and cue-induced reinstatement of heroin seeking. A heroin prime given to rats in which heroin seeking had been extinguished resulted in a rapid increase in spine density and 
synaptic strength. This group concluded that increased NR2B formed silent synapses in PFC to NAc core connections such that a reinstatement trigger enabled synapses to rapidly develop an LTPlike increase in field-potential strength necessary for resumption of heroin seeking. Based on prior studies of how silent synapses are "unsilenced" it is likely that $\mathrm{Ca}^{2+}$-induced $\mathrm{Ca}^{2+} /$ calmodulindependent protein kinase II (CaMKII) facilitates shuttling of AMPARs from extrasynaptic sites on the plasma membrane to synaptic zones (Kerchner and Nicoll, 2008). In a different study, NR2A knockout mice treated chronically with morphine show reduced somatic withdrawal signs (Inoue et al., 2003). Restoration of NR2A expression selectively in the NAc allowed for the expression of somatic withdrawal signs. The NAc is not usually perceived as a substrate for somatic withdrawal, but this and other studies (Harris and Aston-Jones, 1994; Chartoff et al., 2009) indicate that it is a necessary - and perhaps even sufficient component.

Morphine dependence and withdrawal may lower the threshold for LTP-like processes through a cAMP mechanism. Acute stimulation of Gai-coupled MORs leads to a decrease in cAMP levels (Childers, 1991). In the presence of chronic morphine, however, molecular adaptations occur such that adenylate cyclase activity increases and cAMP levels return to approximately normal; when morphine is discontinued or the opioid receptor antagonist naloxone is administered, cAMP levels dramatically increase (for review, see Nestler and Aghajanian, 1997). Previously we have shown that naloxone-precipitated withdrawal increases levels of phosphorylated CREB (P-CREB) and P-GluR1 ${ }^{\text {Ser845 }}$ in the NAc of morphine-dependent rats (Figure 3A; Chartoff et al., 2006). Using primary cultures of dissociated striatal neurons, we demonstrated that administration of naloxone to cultures treated chronically with morphine enabled the dopamine D1 receptor agonist SKF 82958 to super-induce P-GluR1 ${ }^{\text {Ser845, }}$, an effect blocked by the selective PKA inhibitor, H89 (Figure 3B). Together, these data predict that surface expression (although not necessarily synaptic expression) of GluR1 subunits would increase during opioid withdrawal. This has not been directly tested, although it has been shown that targeted overexpression of GluR1 (but not GluR2) in the NAc produces anhedonia in the intracranial selfstimulation paradigm (Todtenkopf et al., 2006). One caveat may be that withdrawal-induced increases in extracellular glutamate trigger internalization/desensitization of AMPARs - reminiscent of synaptic scaling (Turrigiano, 2008). These predictions are not mutually exclusive, as glutamate-triggered desensitization would likely be a pan-NAc effect whereas PKA-mediated PGluR $1^{\text {Ser845 }}$ and membrane insertion would likely occur only in MOR-expressing neurons.

As discussed in the beginning of this review, acute and protracted OWS has been shown clinically to precipitate relapse. Using an animal model of relapse, several studies have shown that glutamate release and AMPAR activation in the NAc core are necessary for reinstatement of heroin seeking after a period of withdrawal in which operant responding for heroin is extinguished (Bossert et al., 2006, 2011, 2012; LaLumiere and Kalivas, 2008). These studies raise an important issue - namely whether a heroin prime or a heroin-associated context (used as triggers for reinstatement) produces a negative affective state akin to OWS or a drug-like rewarding state that drives reinstatement. Increasing evidence supports the former: activation of NAc neurons (i.e., via glutamatergic transmission) is associated with aversive states (Carlezon and Thomas, 2009). The relevance of this hypothesis to heroin reinstatement studies remains to be tested.

\section{MOR-GLUTAMATE INTERACTIONS IN THE VTA}

During morphine withdrawal GABA release is increased due to MOR-induced upregulation of cAMP signaling (Figure 2, GABAergic neuron, Withdrawal condition; Bonci and Williams, 1996, 1997), and glutamate release is decreased due to an increase in the potency of $\mathrm{GABA}_{\mathrm{B}}$ receptor and $\mathrm{mGluR}$-mediated presynaptic inhibition (Figure 2, Glutamate neuron, Withdrawal condition; Manzoni and Williams, 1999). Combined, these effects lead to a strong suppression of dopamine neuron activation (Diana et al., 1995). Interestingly, it has been found that chronic morphine's almost ubiquitous upregulation of adenylate cyclase does not play a role in modulation of glutamate release in the VTA during withdrawal (Manzoni and Williams, 1999) leaving the mechanism for augmented inhibition of glutamate release unknown for now.

One confusing aspect of MOR-glutamate interactions in the VTA during opioid withdrawal is that the actual time course of withdrawal-induced effects on glutamatergic neurotransmission is not known. Putting together available data, the immediate effect of withdrawal is relief of MOR-mediated inhibition of glutamatergic and GABAergic afferents to dopamine neurons and an increase in glutamate and GABA release. Subsequently, glutamate and GABA engage the more slowly acting metabotropic mGluR2/3 and $\mathrm{GABA}_{\mathrm{B}}$ receptors on glutamatergic terminals resulting in decreased glutamatergic synaptic transmission (Figure 2, Glutamate neuron, Withdrawal condition). The complexity of this scenario raises the possibility that plasticity within micro-regions containing MOR-expressing GABA and glutamate terminals that synapse onto dopamine neurons results in fine temporal and spatial control over synaptic communication. How this affects NMDAR and AMPAR function is not known, although one prediction is that AMPARs get promoted to synapses within microregions in which glutamate release is decreased and removed from synapses in which glutamate release is increased. This selective strengthening of synapses could provide a mechanism for associative learning that occurs with conditioned withdrawal (Myers and Carlezon, 2010b).

\section{RELAPSE \\ CLINICAL DESCRIPTION}

In humans, the risk for relapse decreases the longer a person remains abstinent. This is thought to be due, in part, to the fact that the most powerful motivation to relapse stems from the desire to alleviate the initial physiological withdrawal. Opioid agonist therapies are extremely successful in treating this phase of the OWS. Unfortunately, withdrawal from these medications also produces withdrawal signs that can trigger relapse. Furthermore, they do not treat other facets of abstinence, including cue reactivity.

Abstinent addicts are at high risk for relapse due to conditioned craving and withdrawal elicited by previously drug-paired cues 
(Wikler, 1973; O’Brien et al., 1986). In fact, heroin addicts report that the temptation or urge to use drug is elicited most powerfully by drug-paired cues (Heather et al., 1991). Incentive salience is the term that describes the unconscious and hypervigilant focus on rapid identification of any environmental cues that predict access to opioid using. During early recovery treatment, patients are taught to avoid high-risk "people, places, and things" to prevent cue-conditioned relapse. However, they are often baffled by their inability to reliably detect and avoid such triggers. This is because incentive salience is not a learned association within conscious awareness. A common clinical example would be that of an abstinent opioid addict being drawn to a person who is actively using while not recognizing that behavioral cues associated with that person's drug use, and not his/her personality, are the source of interpersonal interest. On a positive note, cue reactivity wanes with time, and it appears as if the success of abstinence itself begins to provide a protective factor against relapse (see Epstein et al., 2006).

\section{MORPHINE-GLUTAMATE INTERACTIONS IN THE NAC}

The majority of studies examining the role of NAc glutamatergic transmission in animal models of opioid relapse utilize the reinstatement model of drug seeking, in which the operant behavior producing contingent opioid administration is extinguished over time and then reinstated with non-contingent drug, cue, or stress presentation (Shalev etal., 2002). There is little data on how glutamatergic transmission regulates negative reinforcement mechanisms stemming from OWS. In a seminal study, LaLumiere and Kalivas (2008) demonstrated in rats that a non-contingent heroin prime or discrete cues previously paired with heroin infusions increased extracellular glutamate in the NAc core via increased synaptic transmission from PFC afferents. Intra-NAc core AMPAR blockade prevented reinstatement of heroin seeking. A separate study showed that microinjections of the mGluR2/3 receptor agonist LY379268 into the NAc shell, which inhibits evoked glutamate release from cortical afferents, reduced context-induced reinstatement of heroin seeking (Bossert et al., 2006). Interestingly, this group proposed that the reduction in heroin seeking was due to decreases in the motivational significance of the heroin context rather than to interference with memory retrieval. This is consistent with the idea that incentive salience underlies the power of a drug-paired cue to evoke drug-seeking behavior, and raises the possibility that heroinassociated cues increase synaptic glutamate release in the NAc thus producing an aversive state (Carlezon and Thomas, 2009; although see Stewart etal., 1984). Finally, chronic heroin selfadministration increases NR2B subunits in the NAc (see Chronic Opioids). This is necessary for a heroin prime-induced increase in synaptic strength, dendritic spine enlargement, and reinstatement of heroin seeking after a period of extinction (Shen et al., 2011).

Although the VTA has been implicated in conditioned and unconditioned reinforcing effects of opioids (Stewart et al., 1984), and intra-VTA microinjections of the mGluR2/3 agonist LY379268 partially alleviate context-induced reinstatement of heroin seeking (Bossert et al., 2004), there is relatively little data on VTA glutamatergic transmission and relapse.

\section{IMPLICATIONS FOR MEDICATIONS DEVELOPMENT}

Opioid dependence and withdrawal disrupts excitatory neurotransmission in reward-related brain circuits, which contributes to negative affective states associated with OWS and to corruption of motivated behavior away from natural rewards toward obtaining and taking drug. Efforts are underway to develop pharmacotherapies that target these aspects of addiction, but there has not been a major advancement in treatment options. Given what is known about the effects of MOR activation on glutamatergic transmission within the mesolimbic dopamine system, some ideas for targets emerge (see Figures 1 and 2).

- Extracellular glutamate levels are increased in NAc and VTA during opioid withdrawal.

- NMDAR levels/function is increased in both the NAc and VTA with chronic opioids.

- MOR-expressing neurons become hyperexcitable with opioid withdrawal.

- GluR1 AMPAR subunits decrease in NAc and increase in VTA with chronic opioids.

Some compounds that act on these targets and have shown some promise in the treatment of addiction include:

- Topiramate/Lamotrigine - Used therapeutically as anticonvulsants and mood stabilizers. Mechanisms of action include inhibition of voltage-gated $\mathrm{Na}^{+}$and $\mathrm{Ca}^{2+}$ channels and activation of $\mathrm{GABA}_{\mathrm{A}}$ receptors (Rogawski and Loscher, 2004). May also block GluR5-containing AMPARs. Showed some promise as an adjunct during detoxification in a small study (Zullino et al., 2004).

- Lacosamide - Used therapeutically as an anticonvulsant. Mechanism of action is to enhance slow inactivation of voltage-gated $\mathrm{Na}^{+}$channels (Beyreuther et al., 2007). Reduces the rewardrelated effects of cocaine at doses that do not impact motor capacity (Beguin et al., 2012).

- Memantine - Used to treat cognitive decline in Alzheimer's patients. Primary mechanism of action is as a noncompetitive NMDAR antagonist. Reduced expression of naloxoneprecipitated physical withdrawal signs in heroin-dependent patients (Bisaga et al., 2001).

None of these compounds have demonstrated remarkable effects, indicating that specifically targeting glutamate transmission will not be a panacea for opioid addiction. Notably none have been tested on protracted withdrawal signs such as anxiety and depression or on conditioned withdrawal or craving.

\section{CONCLUSION}

$\mathrm{Mu}$ opioid receptor agonists such as morphine and heroin perturb the delicate balance of neurophysiological communication maintained by endogenous opioid peptides in the brain. The fact that a heroin "rush" or naloxone-precipitated withdrawal signs in opiate-dependent individuals can be felt within seconds of intravenous injection is evidence that the onset and offset of MOR activation can have rapid effects on cellular activity. The fact that some people develop a loss of control over opiate intake such that they engage in compulsive drug taking behaviors - despite severe negative consequences - is evidence that activation of MORcoupled $\mathrm{G}$ proteins can have slower effects to alter neural circuits 
regulating motivated behavior. And the fact that drug-associated cues or contexts trigger relapse at some point in almost all opiate addicts trying to stay abstinent is evidence that activation of MORcoupled $G$ proteins facilitates long-lasting synaptic plasticity that maintains drug-related memories. As discussed in this review, this constellation of MOR effects stems in a large part from crosstalk between MOR-associated $\mathrm{G}$ protein signaling and glutamatergic neurotransmission.

\section{ACKNOWLEDGMENTS}

Funded by the National Institute on Drug Abuse (NIDA) grants DA023606 (to Elena H. Chartoff) and CTN: National Institute on Drug Abuse U10DA15831 (to Hilary S. Connery).

\section{REFERENCES}

Aghajanian, G. K., Kogan, J. H., and Moghaddam, B. (1994). Opiate withdrawal increases glutamate and aspartate efflux in the locus coeruleus: an in vivo microdialysis study. Brain Res. 636, 126-130. doi: 10.1016/0006-8993(94) 90186-4

Alderson, H. L., Parkinson, J. A., Robbins, T. W., and Everitt, B. J. (2001). The effects of excitotoxic lesions of the nucleus accumbens core or shell regions on intravenous heroin self-administration in rats. Psychopharmacology (Berl.) 153, 455-463. doi: 10.1007/s002130000634

Anggono, V., and Huganir, R. L. (2012). Regulation of AMPA receptor trafficking and synaptic plasticity. Curr. Opin. Neurobiol. 22, 461-469. doi: 10.1016/j.conb.2011.12.006

Badiani, A., Belin, D., Epstein, D., Calu, D., and Shaham, Y. (2011). Opiate versus psychostimulant addiction: the differences do matter. Nat. Rev. Neurosci. 12, 685-700. doi: 10.1038/nrn3104

Bailey, C. P., and Connor, M. (2005). Opioids: cellular mechanisms of tolerance and physical dependence. Curr. Opin. Pharmacol. 5, 60-68. doi: 10.1016/j.coph.2004.08.012

Bajo, M., Crawford, E. F., Roberto, M., Madamba, S. G., and Siggins, G. R. (2006). Chronic morphine treatment alters expression of $N$-methyl-D-aspartate receptor subunits in the extended amygdala. J. Neurosci. Res. 83, 532-537. doi: 10.1002/jnr.20756

Beattie, E. C., Carroll, R. C., Yu, X., Morishita, W., Yasuda, H., Von Zastrow, M., et al. (2000). Regulation of AMPA receptor endocytosis by a signaling mechanism shared with LTD. Nat. Neurosci. 3, 1291-1300. doi: 10.1038/81823

Becerra, L., Breiter, H. C., Wise, R., Gonzalez, R. G., and Borsook, D. (2001). Reward circuitry activation by noxious thermal stimuli. Neuron 32, 927-946. doi: 10.1016/S0896-6273(01)00533-5

Beguin, C., Potter, D. N., Carlezon, W. A. Jr., Stohr, T., and Cohen, B. M. (2012). Effects of the anticonvulsant lacosamide compared to valproate and lamotrigine on cocaine-enhanced reward in rats. Brain Res. 1479, 44-51. doi: 10.1016/j.brainres.2012.08.030

Berendse, H. W., Galis-De Graaf, Y., and Groenewegen, H. J. (1992). Topographical organization and relationship with ventral striatal compartments of prefrontal corticostriatal projections in the rat. J. Comp. Neurol. 316, 314-347. doi: $10.1002 /$ cne. 903160305

Berendse, H. W., and Groenewegen, H. J. (1990). Organization of the thalamostriatal projections in the rat, with special emphasis on the ventral striatum. J. Comp. Neurol. 299, 187-228. doi: 10.1002/cne.902990206

Berridge, K. C., and Robinson, T. E. (1998). What is the role of dopamine in reward: hedonic impact, reward learning, or incentive salience? Brain Res. Brain Res. Rev. 28, 309-369. doi: 10.1016/S0165-0173(98)00019-8

Beyreuther, B. K., Freitag, J., Heers, C., Krebsfanger, N., Scharfenecker, U., and Stohr, T. (2007). Lacosamide: a review of preclinical properties. CNS Drug Rev. 13, 21-42. doi: 10.1111/j.1527-3458.2007.00001.x

Bisaga, A., Comer, S. D., Ward, A. S., Popik, P., Kleber, H. D., and Fischman, M. W. (2001). The NMDA antagonist memantine attenuates the expression of opioid physical dependence in humans. Psychopharmacology (Berl.) 157, 1-10. doi: $10.1007 / \mathrm{s} 002130100739$

Bonci, A., and Williams, J. T. (1996). A common mechanism mediates long-term changes in synaptic transmission after chronic cocaine and morphine. Neuron 16 , 631-639. doi: 10.1016/S0896-6273(00)80082-3
Bonci, A., and Williams, J. T. (1997). Increased probability of GABA release during withdrawal from morphine. J. Neurosci. 17, 796-803.

Bossert, J. M., Gray, S. M., Lu, L., and Shaham, Y. (2006). Activation of group II metabotropic glutamate receptors in the nucleus accumbens shell attenuates context-induced relapse to heroin seeking. Neuropsychopharmacology 31, 21972209. doi: 10.1038/sj.npp.1300977

Bossert, J. M., Liu, S. Y., Lu, L., and Shaham, Y. (2004). A role of ventral tegmental area glutamate in contextual cue-induced relapse to heroin seeking. J. Neurosci. 24, 10726-10730. doi: 10.1523/JNEUROSCI.3207-04.2004

Bossert, J. M., Stern, A. L., Theberge, F. R., Cifani, C., Koya, E., Hope, B. T., et al. (2011). Ventral medial prefrontal cortex neuronal ensembles mediate context-induced relapse to heroin. Nat. Neurosci. 14, 420-422. doi: 10.1038/ nn. 2758

Bossert, J. M., Stern, A. L., Theberge, F. R., Marchant, N. J., Wang, H. L., Morales, M., et al. (2012). Role of projections from ventral medial prefrontal cortex to nucleus accumbens shell in context-induced reinstatement of heroin seeking. J. Neurosci. 32, 4982-4991. doi: 10.1523/JNEUROSCI.0005-12.2012

Botreau, F., Paolone, G., and Stewart, J. (2006). d-Cycloserine facilitates extinction of a cocaine-induced conditioned place preference. Behav. Brain Res. 172, 173-178. doi: 10.1016/j.bbr.2006.05.012

Bourdy, R., and Barrot, M. (2012). A new control center for dopaminergic systems: pulling the VTA by the tail. Trends Neurosci. 35, 681-690. doi: 10.1016/j.tins.2012.06.007

Bozarth, M. A. (1987). Neuroanatomical boundaries of the reward-relevant opiatereceptor field in the ventral tegmental area as mapped by the conditioned place preference method in rats. Brain Res. 414, 77-84. doi: 10.1016/00068993(87)91327-8

Bozarth, M. A., and Wise, R. A. (1981). Heroin reward is dependent on a dopaminergic substrate. Life Sci. 29, 1881-1886. doi: 10.1016/0024-3205(81) 90519-1

Bozarth, M. A., and Wise, R. A. (1983). Neural substrates of opiate reinforcement. Prog. Neuropsychopharmacol. Biol. Psychiatry 7, 569-575. doi: 10.1016/02785846(83)90027-1

Brebner, K., Wong, T. P., Liu, L., Liu, Y., Campsall, P., Gray, S., et al. (2005). Nucleus accumbens long-term depression and the expression of behavioral sensitization. Science 310, 1340-1343. doi: 10.1126/science.1116894

Britt, M. D., and Wise, R. A. (1983). Ventral tegmental site of opiate reward: antagonism by a hydrophilic opiate receptor blocker. Brain Res. 258, 105-108. doi: 10.1016/0006-8993(83)91232-5

Broekkamp, C. L., Van Den Bogaard, J. H., Heijnen, H. J., Rops, R. H., Cools, A. R., and Van Rossum, J. M. (1976). Separation of inhibiting and stimulating effects of morphine on self-stimulation behaviour by intracerebral microinjections. Eur. J. Pharmacol. 36, 443-446. doi: 10.1016/0014-2999(76)90099-6

Brog, J. S., Salyapongse, A., Deutch, A. Y., and Zahm, D. S. (1993). The patterns of afferent innervation of the core and shell in the "accumbens" part of the rat ventral striatum: immunohistochemical detection of retrogradely transported fluoro-gold. J. Comp. Neurol. 338, 255-278. doi: 10.1002/cne.903 380209

Brown, M. T., Bellone, C., Mameli, M., Labouebe, G., Bocklisch, C., Balland, B., et al. (2010). Drug-driven AMPA receptor redistribution mimicked by selective dopamine neuron stimulation. PLOS ONE 5:e15870. doi: 10.1371/journal.pone. 0015870

Burnashev, N., Monyer, H., Seeburg, P. H., and Sakmann, B. (1992). Divalent ion permeability of AMPA receptor channels is dominated by the edited form of a single subunit. Neuron 8, 189-198. doi: 10.1016/0896-6273(92)90120-3

Carelli, R. M. (2002). The nucleus accumbens and reward: neurophysiological investigations in behaving animals. Behav. Cogn. Neurosci. Rev. 1, 281-296. doi: $10.1177 / 1534582302238338$

Carlezon, W. A. Jr., Boundy, V. A., Haile, C. N., Lane, S. B., Kalb, R. G., Neve, R. L., et al. (1997). Sensitization to morphine induced by viral-mediated gene transfer. Science 277, 812-814. doi: 10.1126/science.277.5327.812

Carlezon, W. A. Jr., Haile, C. N., Coppersmith, R., Hayashi, Y., Malinow, R., Neve, R. L., et al. (2000). Distinct sites of opiate reward and aversion within the midbrain identified using a herpes simplex virus vector expressing GluR1. J. Neurosci. 20, RC62.

Carlezon, W. A. Jr., and Nestler, E. J. (2002). Elevated levels of GluR1 in the midbrain: a trigger for sensitization to drugs of abuse? Trends Neurosci. 25, 610-615. doi: 10.1016/S0166-2236(02)02289-0 
Carlezon, W. A. Jr., and Thomas, M. J. (2009). Biological substrates of reward and aversion: a nucleus accumbens activity hypothesis. Neuropharmacology 56(Suppl. 1), 122-132. doi: 10.1016/j.neuropharm.2008.06.075

Carlezon, W. A. Jr., and Wise, R. A. (1996a). Microinjections of phencyclidine (PCP) and related drugs into nucleus accumbens shell potentiate medial forebrain bundle brain stimulation reward. Psychopharmacologia 128, 413-420. doi: 10.1007/s002130050151

Carlezon, W. A. Jr., and Wise, R. A. (1996b). Rewarding actions of phencyclidine and related drugs in nucleus accumbens shell and frontal cortex. J. Neurosci. 16, 3112-3122.

Carr, D. B., and Sesack, S. R. (2000). Projections from the rat prefrontal cortex to the ventral tegmental area: target specificity in the synaptic associations with mesoaccumbens and mesocortical neurons. J. Neurosci. 20, 3864-3873.

Chartoff, E. H., Barhight, M. F., Mague, S. D., Sawyer, A. M., and Carlezon, W. A. Jr. (2009). Anatomically dissociable effects of dopamine D1 receptor agonists on reward and relief of withdrawal in morphine-dependent rats. Psychopharmacology (Berl.) 204, 227-239. doi: 10.1007/s00213-008-1454-7

Chartoff, E. H., Mague, S. D., Barhight, M. F., Smith, A. M., and Carlezon, W. A. Jr. (2006). Behavioral and molecular effects of dopamine D1 receptor stimulation during naloxone-precipitated morphine withdrawal. J. Neurosci. 26, 6450-6457. doi: 10.1523/JNEUROSCI.0491-06.2006

Chartoff, E. H., Papadopoulou, M., Konradi, C., and Carlezon, W. A. Jr. (2003a). Dopamine-dependent increases in phosphorylation of cAMP response element binding protein (CREB) during precipitated morphine withdrawal in primary cultures of rat striatum. J. Neurochem. 87, 107-118. doi: 10.1046/j.14714159.2003.01992.x

Chartoff, E. H., Papadopoulou, M., Konradi, C., and Carlezon, W. A. Jr. (2003b). Effects of naloxone-precipitated morphine withdrawal on glutamate-mediated signaling in striatal neurons in vitro. Ann. N. Y. Acad. Sci. 1003, 368-371. doi: 10.1196/annals. 1300.028

Chen, Q., and Reiner, A. (1996). Cellular distribution of the NMDA receptor NR2A/2B subunits in the rat striatum. Brain Res. 743, 346-352. doi: 10.1016/S0006-8993(96)01098-0

Chen, Y., Mestek, A., Liu, J., and Yu, L. (1993). Molecular cloning of a rat kappa opioid receptor reveals sequence similarities to the mu and delta opioid receptors. Biochem. J. 295(Pt 3), 625-628.

Cherubini, E., Herrling, P. L., Lanfumey, L., and Stanzione, P. (1988). Excitatory amino acids in synaptic excitation of rat striatal neurones in vitro. J. Physiol. 400, 677-690.

Chieng, B., and Williams, J. T. (1998). Increased opioid inhibition of GABA release in nucleus accumbens during morphine withdrawal. J. Neurosci. 18, 7033-7039.

Childers, S. R. (1991). Opioid receptor-coupled second messenger systems. Life Sci. 48, 1991-2003. doi: 10.1016/0024-3205(91)90154-4

Citri, A., and Malenka, R. C. (2008). Synaptic plasticity: multiple forms, functions, and mechanisms. Neuropsychopharmacology 33, 18-41. doi: 10.1038/sj.npp.1301559

Clem, R. L., and Barth, A. (2006). Pathway-specific trafficking of native AMPARs by in vivo experience. Neuron 49, 663-670. doi: 10.1016/j.neuron.2006.01.019

Contarino, A., and Papaleo, F. (2005). The corticotropin-releasing factor receptor-1 pathway mediates the negative affective states of opiate withdrawal. Proc. Natl. Acad. Sci. U.S.A. 102, 18649-18654. doi: 10.1073/pnas.0506999102

David, V., and Cazala, P. (2000). Anatomical and pharmacological specificity of the rewarding effect elicited by microinjections of morphine into the nucleus accumbens of mice. Psychopharmacology (Berl.) 150, 24-34. doi: $10.1007 / \mathrm{s} 002130000425$

Denier, N., Gerber, H., Vogel, M., Klarhofer, M., Riecher-Rossler, A., Wiesbeck, G. A., et al. (2013). Reduction in cerebral perfusion after heroin administration: a resting state arterial spin labeling study. PLoS ONE 8:e71461. doi: 10.1371/journal.pone.0071461

Desole, M. S., Esposito, G., Fresu, L., Migheli, R., Enrico, P., Mura, M. A., et al. (1996). Effects of morphine treatment and withdrawal on striatal and limbic monoaminergic activity and ascorbic acid oxidation in the rat. Brain Res. 723, 154-161. doi: 10.1016/0006-8993(96)00235-1

Devine, D. P., and Wise, R. A. (1994). Self-administration of morphine, DAMGO, and DPDPE into the ventral tegmental area of rats. J. Neurosci. 14, 1978-1984.

Diana, M., Pistis, M., Muntoni, A., and Gessa, G. (1995). Profound decrease of mesolimbic dopaminergic neuronal activity in morphine withdrawn rats. $J$. Pharmacol. Exp. Ther. 272, 781-785.
Di Chiara, G., and Imperato, A. (1988a). Drugs abused by humans preferentially increase synaptic dopamine concentrations in the mesolimbic system of freely moving rats. Proc. Natl. Acad. Sci. U.S.A. 85, 5274-5278. doi: 10.1073/pnas.85.14.5274

Di Chiara, G., and Imperato, A. (1988b). Opposite effects of mu and kappa opiate agonists on dopamine release in the nucleus accumbens and in the dorsal caudate of freely moving rats. J. Pharmacol. Exp. Ther. 244, 1067-1080.

Dingledine, R., Borges, K., Bowie, D., and Traynelis, S. F. (1999). The glutamate receptor ion channels. Pharmacol. Rev. 51, 7-61.

Dole, V. P., Nyswander, M. E., and Kreek, M. J. (1966). Narcotic blockade. Arch. Intern. Med. 118, 304-309. doi: 10.1001/archinte.1966.00290160004002

Duman, R. S., Tallman, J. F., and Nestler, E. J. (1988). Acute and chronic opiateregulation of adenylate cyclase in brain: specific effects in locus coeruleus. $J$. Pharmacol. Exp. Ther. 246, 1033-1039.

Dunah, A. W., Yasuda, R. P., Luo, J., Wang, Y., Prybylowski, K. L., and Wolfe, B. B. (1999). Biochemical studies of the structure and function of the N-methylD-aspartate subtype of glutamate receptors. Mol. Neurobiol. 19, 151-179. doi: 10.1007/BF02743658

Dworkin, S. I., Guerin, G. F., Goeders, N. E., and Smith, J. E. (1988). Kainic acid lesions of the nucleus accumbens selectively attenuate morphine self-administration. Pharmacol. Biochem. Behav. 29, 175-181. doi: 10.1016/00913057(88)90292-4

Enrico, P., Mura, M. A., Esposito, G., Serra, P., Migheli, R., De Natale, G., et al. (1998). Effect of naloxone on morphine-induced changes in striatal dopamine metabolism and glutamate, ascorbic acid and uric acid release in freely moving rats. Brain Res. 797, 94-102. doi: 10.1016/S0006-8993(98)00371-0

Epstein, D. H., Preston, K. L., Stewart, J., and Shaham, Y. (2006). Toward a model of drug relapse: an assessment of the validity of the reinstatement procedure. Psychopharmacology (Berl.) 189, 1-16. doi: 10.1007/s00213-006-0529-6

Esteban, J. A., Shi, S. H., Wilson, C., Nuriya, M., Huganir, R. L., and Malinow, R. (2003). PKA phosphorylation of AMPA receptor subunits controls synaptic trafficking underlying plasticity. Nat. Neurosci. 6, 136-143. doi: 10.1038/ nn997

Fields, H. L., Hjelmstad, G. O., Margolis, E. B., and Nicola, S. M. (2007). Ventral tegmental area neurons in learned appetitive behavior and positive reinforcement. Annu. Rev. Neurosci. 30, 289-316. doi: 10.1146/annurev.neuro.30.051606. 094341

Fitzgerald, L. W., Ortiz, J., Hamedani, A. G., and Nestler, E. J. (1996). Drugs of abuse and stress increase the expression of GluR1 and NMDAR1 glutamate receptor subunits in the rat ventral tegmental area: common adaptations among crosssensitizing agents. J. Neurosci. 16, 274-282.

Floresco, S. B., West, A. R., Ash, B., Moore, H., and Grace, A. A. (2003). Afferent modulation of dopamine neuron firing differentially regulates tonic and phasic dopamine transmission. Nat. Neurosci. 6, 968-973. doi: 10.1038/nn1103

Fudala, P. J., Bridge, T. P., Herbert, S., Williford, W. O., Chiang, C. N., Jones, K., et al. (2003). Office-based treatment of opiate addiction with a sublingual-tablet formulation of buprenorphine and naloxone. N. Engl. J. Med. 349, 949-958. doi: 10.1056/NEJMoa022164

Garzon, M., and Pickel, V. M. (2001). Plasmalemmal mu-opioid receptor distribution mainly in nondopaminergic neurons in the rat ventral tegmental area. Synapse 41, 311-328. doi: 10.1002/syn.1088

Georges, F., Le Moine, C., and Aston-Jones, G. (2006). No effect of morphine on ventral tegmental dopamine neurons during withdrawal. J. Neurosci. 26, 57205726. doi: 10.1523/JNEUROSCI.5032-05.2006

Georges, F., Stinus, L., Bloch, B., and Le Moine, C. (1999). Chronic morphine exposure and spontaneous withdrawal are associated with modifications of dopamine receptor and neuropeptide gene expression in the rat striatum. Eur. J. Neurosci. 11, 481-490. doi: 10.1046/j.1460-9568.1999.00462.x

Gerfen, C. R. (1992). The neostriatal mosaic: multiple levels of compartmental organization. Trends Neurosci. 15, 133-139. doi: 10.1016/0166-2236(92)90355-C Gerfen, C. R., Engber, T. M., Mahan, L. C., Susel, Z., Chase, T. N., Monsma, F. J., etal. (1990). D1 and D2 dopamine receptor-regulated gene expression of striatonigral and striatopallidal neurons. Science 250, 1429-1432. doi: $10.1126 /$ science. 2147780

Gerrits, M. A., and Van Ree, J. M. (1996). Effect of nucleus accumbens dopamine depletion on motivational aspects involved in initiation of cocaine and heroin self-administration in rats. Brain Res. 713, 114-124. doi: 10.1016/00068993(95)01491-8 
Giacchino, J. L., and Henriksen, S. J. (1996). Systemic morphine and local opioid effects on neuronal activity in the medial prefrontal cortex. Neuroscience 70 , 941-949. doi: 10.1016/0306-4522(95)00409-2

Glass, M. J., Lane, D. A., Colago, E. E., Chan, J., Schlussman, S. D., Zhou, Y., et al. (2008). Chronic administration of morphine is associated with a decrease in surface AMPA GluR1 receptor subunit in dopamine D1 receptor expressing neurons in the shell and non-D1 receptor expressing neurons in the core of the rat nucleus accumbens. Exp. Neurol. 210, 750-761. doi: 10.1016/j.expneurol.2008. 01.012

Glass, M. J., Vanyo, L., Quimson, L., and Pickel, V. M. (2009). Ultrastructural relationship between $N$-methyl-D-aspartate-NR1 receptor subunit and mu-opioid receptor in the mouse central nucleus of the amygdala. Neuroscience 163, 857-867. doi: 10.1016/j.neuroscience.2009.07.020

Goeders, N. E., Lane, J. D., and Smith, J. E. (1984). Self-administration of methionine enkephalin into the nucleus accumbens. Pharmacol. Biochem. Behav. 20, 451-455. doi: 10.1016/0091-3057(84)90284-3

Gonzalez, P., Cabello, P., Germany, A., Norris, B., and Contreras, E. (1997). Decrease of tolerance to, and physical dependence on morphine by, glutamate receptor antagonists. Eur. J. Pharmacol. 332, 257-262. doi: 10.1016/S0014-2999(97) 01099-6

Grace, A. A., Floresco, S. B., Goto, Y., and Lodge, D. J. (2007). Regulation of firing of dopaminergic neurons and control of goal-directed behaviors. Trends Neurosci. 30, 220-227. doi: 10.1016/j.tins.2007.03.003

Gracy, K. N., Svingos, A. L., and Pickel, V. M. (1997). Dual ultrastructural localization of mu-opioid receptors and NMDA-type glutamate receptors in the shell of the rat nucleus accumbens. J. Neurosci. 17, 4839-4848.

Groenewegen, H. J., Vermeulen-Van Der Zee, E., Te Kortschot, A., and Witter, M. P. (1987). Organization of the projections from the subiculum to the ventral striatum in the rat. A study using anterograde transport of Phaseolus vulgaris leucoagglutinin. Neuroscience 23, 103-120. doi: 10.1016/0306-4522(87) 90275-2

Gysling, K., and Wang, R. Y. (1983). Morphine-induced activation of A10 dopamine neurons in the rat. Brain Res. 277, 119-127. doi: 10.1016/0006-8993(83)90913-7

Haber, S. N., Fudge, J. L., and Mcfarland, N. R. (2000). Striatonigrostriatal pathways in primates form an ascending spiral from the shell to the dorsolateral striatum. J. Neurosci. 20, 2369-2382.

Haber, S. N., and Knutson, B. (2010). The reward circuit: linking primate anatomy and human imaging. Neuropsychopharmacology 35, 4-26. doi: 10.1038/npp.2009.129

Haber, S. N., Lynd, E., Klein, C., and Groenewegen, H. J. (1990). Topographic organization of the ventral striatal efferent projections in the rhesus monkey: an anterograde tracing study. J. Comp. Neurol. 293, 282-298. doi: $10.1002 /$ cne. 902930210

Harris, G. C., and Aston-Jones, G. (1994). Involvement of D2 dopamine receptors in the nucleus accumbens in the opiate withdrawal syndrome. Nature 371, 155-157. doi: $10.1038 / 371155 \mathrm{a} 0$

Harris, G. C., Wimmer, M., Byrne, R., and Aston-Jones, G. (2004). Glutamateassociated plasticity in the ventral tegmental area is necessary for conditioning environmental stimuli with morphine. Neuroscience 129, 841-847. doi: 10.1016/j.neuroscience.2004.09.018

Heather, N., Stallard, A., and Tebbutt, J. (1991). Importance of substance cues in relapse among heroin users: comparison of two methods of investigation. Addict. Behav. 16, 41-49. doi: 10.1016/0306-4603(91)90038-J

Heine, M., Groc, L., Frischknecht, R., Beique, J. C., Lounis, B., Rumbaugh, G., et al. (2008). Surface mobility of postsynaptic AMPARs tunes synaptic transmission. Science 320, 201-205. doi: 10.1126/science.1152089

Herrold, A. A., Persons, A. L., and Napier, T. C. (2013). Cellular distribution of AMPA receptor subunits and mGlu5 following acute and repeated administration of morphine or methamphetamine. J. Neurochem. 126, 503-517. doi: $10.1111 /$ jnc. 12323

Hokfelt, T., Broberger, C., Xu, Z. Q., Sergeyev, V., Ubink, R., and Diez, M. (2000). Neuropeptides - an overview. Neuropharmacology 39, 1337-1356. doi: 10.1016/S0028-3908(00)00010-1

Hollmann, M., Hartley, M., and Heinemann, S. (1991). $\mathrm{Ca}^{2+}$ permeability of KAAMPA - gated glutamate receptor channels depends on subunit composition. Science 252, 851-853. doi: 10.1126/science.1709304

Hollmann, M., and Heinemann, S. (1994). Cloned glutamate receptors. Annu. Rev. Neurosci. 17, 31-108. doi: 10.1146/annurev.ne.17.030194.000335
Hu, X. T., and White, F. J. (1996). Glutamate receptor regulation of rat nucleus accumbens neurons in vivo. Synapse 23, 208-218. doi: 10.1002/(SICI)10982396(199607)23:3<208::AID-SYN10>3.0.CO;2-V

Hyman, S. E., Malenka, R. C., and Nestler, E. J. (2006). Neural mechanisms of addiction: the role of reward-related learning and memory. Annu. Rev. Neurosci. 29, 565-598. doi: 10.1146/annurev.neuro.29.051605.113009

Ikemoto, S. (2007). Dopamine reward circuitry: two projection systems from the ventral midbrain to the nucleus accumbens-olfactory tubercle complex. Brain Res. Rev. 56, 27-78. doi: 10.1016/j.brainresrev.2007.05.004

Ikemoto, S., and Panksepp, J. (1999). The role of nucleus accumbens dopamine in motivated behavior: a unifying interpretation with special reference to rewardseeking. Brain Res. Brain Res. Rev. 31, 6-41. doi: 10.1016/S0165-0173(99) 00023-5

Inoue, M., Mishina, M., and Ueda, H. (2003). Locus-specific rescue of GluRepsilon1 NMDA receptors in mutant mice identifies the brain regions important for morphine tolerance and dependence. J. Neurosci. 23, 6529-6536.

Jacobs, E. H., Wardeh, G., Smit, A. B., and Schoffelmeer, A. N. (2005). Morphine causes a delayed increase in glutamate receptor functioning in the nucleus accumbens core. Eur. J. Pharmacol. 511, 27-30. doi: 10.1016/j.ejphar.2005. 02.009

Jalabert, M., Bourdy, R., Courtin, J., Veinante, P., Manzoni, O. J., Barrot, M., etal. (2011). Neuronal circuits underlying acute morphine action on dopamine neurons. Proc. Natl. Acad. Sci. U.S.A. 108, 16446-16450. doi: 10.1073/pnas. 1105418108

Jensen, J., Mcintosh, A. R., Crawley, A. P., Mikulis, D. J., Remington, G., and Kapur, S. (2003). Direct activation of the ventral striatum in anticipation of aversive stimuli. Neuron 40, 1251-1257. doi: 10.1016/S0896-6273(03) 00724-4

Jhou, T. C., Geisler, S., Marinelli, M., Degarmo, B. A., and Zahm, D. S. (2009). The mesopontine rostromedial tegmental nucleus: a structure targeted by the lateral habenula that projects to the ventral tegmental area of Tsai and substantia nigra compacta. J. Comp. Neurol. 513, 566-596. doi: 10.1002/cne.21891

Johnson, S. W., and North, R. A. (1992). Opioids excite dopamine neurons by hyperpolarization of local interneurons. J. Neurosci. 12, 483-488.

Johnston, L. D., O’Malley, P. M., Miech, R. A., Bachman, J. G., and Schulenberg, J. E. (2014). Monitoring the Future National Survey Results on Drug Use: 2013 Overview, Key Findings on Adolescent Drug Use. Ann Arbor: University of Michigan.

Ju, W., Morishita, W., Tsui, J., Gaietta, G., Deerinck, T. J., Adams, S. R., et al. (2004). Activity-dependent regulation of dendritic synthesis and trafficking of AMPA receptors. Nat. Neurosci. 7, 244-253. doi: 10.1038/nn1189

Kalivas, P. W. (2009). The glutamate homeostasis hypothesis of addiction. Nat. Rev. Neurosci. 10, 561-572. doi: 10.1038/nrn2515

Kalivas, P. W., Lalumiere, R. T., Knackstedt, L., and Shen, H. (2009). Glutamate transmission in addiction. Neuropharmacology 56(Suppl. 1), 169-173. doi: 10.1016/j.neuropharm.2008.07.011

Kauer, J. A., and Malenka, R. C. (2007). Synaptic plasticity and addiction. Nat. Rev. Neurosci. 8, 844-858. doi: 10.1038/nrn2234

Kawaguchi, Y., Wilson, C. J., Augood, S. J., and Emson, P. C. (1995). Striatal interneurones: chemical, physiological and morphological characterization. Trends Neurosci. 18, 527-535. doi: 10.1016/0166-2236(95)98374-8

Kelley, A. E., and Domesick, V. B. (1982). The distribution of the projection from the hippocampal formation to the nucleus accumbens in the rat: an anterogradeand retrograde-horseradish peroxidase study. Neuroscience 7, 2321-2335. doi: 10.1016/0306-4522(82)90198-1

Kelley, A. E., Domesick, V. B., and Nauta, W. J. (1982). The amygdalostriatal projection in the rat - an anatomical study by anterograde and retrograde tracing methods. Neuroscience 7, 615-630. doi: 10.1016/0306-4522(82)90067-7

Kerchner, G. A., and Nicoll, R. A. (2008). Silent synapses and the emergence of a postsynaptic mechanism for LTP. Nat. Rev. Neurosci. 9, 813-825. doi: $10.1038 / \mathrm{nrn} 2501$

Kessels, H. W., and Malinow, R. (2009). Synaptic AMPA receptor plasticity and behavior. Neuron 61, 340-350. doi: 10.1016/j.neuron.2009.01.015

Khan, Z. U., Gutierrez, A., Martin, R., Penafiel, A., Rivera, A., and De La Calle, A. (2000). Dopamine D5 receptors of rat and human brain. Neuroscience 100, 689-699. doi: 10.1016/S0306-4522(00)00274-8

Konradi, C., Cole, R. L., Heckers, S., and Hyman, S. E. (1994). Amphetamine regulates gene expression in rat striatum via transcription factor CREB. J. Neurosci. $14,5623-5634$. 
Konradi, C., Leveque, J. C., and Hyman, S. E. (1996). Amphetamine and dopamine-induced immediate early gene expression in striatal neurons depends on postsynaptic NMDA receptors and calcium. J. Neurosci. 16, 4231-4239.

Koob, G. F. (1992). Drugs of abuse: anatomy, pharmacology and function of reward pathways. Trends Pharmacol. Sci. 13, 177-184. doi: 10.1016/0165-6147(92) 90060-J

Koob, G. F. (2009). Neurobiological substrates for the dark side of compulsivity in addiction. Neuropharmacology 56(Suppl. 1), 18-31. doi: 10.1016/j.neuropharm.2008.07.043

Koob, G. F., Maldonado, R., and Stinus, L. (1992). Neural substrates of opiate withdrawal. Trends Neurosci. 15, 186-191. doi: 10.1016/0166-2236(92)90171-4

Kosel, M., Noss, R. S., Hammig, R., Wielepp, P., Bundeli, P., Heidbreder, R., et al. (2008). Cerebral blood flow effects of acute intravenous heroin administration. Eur. Neuropsychopharmacol. 18, 278-285. doi: 10.1016/j.euroneuro.2007.11.007

Kreek, M. J., and Koob, G. F. (1998). Drug dependence: stress and dysregulation of brain reward pathways. Drug Alcohol Depend. 51, 23-47. doi: 10.1016/S03768716(98)00064-7

Kuppenbender, K. D., Standaert, D. G., Feuerstein, T. J., Penney, J. B. Jr., Young, A. B., and Landwehrmeyer, G. B. (2000). Expression of NMDA receptor subunit mRNAs in neurochemically identified projection and interneurons in the human striatum. J. Comp. Neurol. 419, 407-421. doi: 10.1002/(SICI)10969861(20000417)419:4<407::AID-CNE1>3.0.CO;2-I

LaLumiere, R. T., and Kalivas, P. W. (2008). Glutamate release in the nucleus accumbens core is necessary for heroin seeking. J. Neurosci. 28, 3170-3177. doi: 10.1523/JNEUROSCI.5129-07.2008

Lane, D. A., Lessard, A. A., Chan, J., Colago, E. E., Zhou, Y., Schlussman, S. D., etal. (2008). Region-specific changes in the subcellular distribution of AMPA receptor GluR1 subunit in the rat ventral tegmental area after acute or chronic morphine administration. J. Neurosci. 28, 9670-9681. doi: 10.1523/JNEUROSCI.2151-08.2008

Law, P. Y., Wong, Y. H., and Loh, H. H. (2000). Molecular mechanisms and regulation of opioid receptor signaling. Annu. Rev. Pharmacol. Toxicol. 40, 389-430. doi: 10.1146/annurev.pharmtox.40.1.389

Le Merrer, J., Becker, J. A., Befort, K., and Kieffer, B. L. (2009). Reward processing by the opioid system in the brain. Physiol. Rev. 89, 1379-1412. doi 10.1152/physrev.00005.2009

Leri, F., Flores, J., Rajabi, H., and Stewart, J. (2003). Effects of cocaine in rats exposed to heroin. Neuropsychopharmacology 28, 2102-2116. doi: 10.1038/sj.npp. 1300284

Li, S. X., Shi, J., Epstein, D. H., Wang, X., Zhang, X. L., Bao, Y. P., et al. (2009). Circadian alteration in neurobiology during 30 days of abstinence in heroin users. Biol. Psychiatry 65, 905-912. doi:10.1016/j.biopsych.2008.11.025

Liu, S. Q., and Cull-Candy, S. G. (2000). Synaptic activity at calcium-permeable AMPA receptors induces a switch in receptor subtype. Nature 405, 454-458. doi: $10.1038 / 35013064$

Lobo, M. K. (2009). Molecular profiling of striatonigral and striatopallidal medium spiny neurons past, present, and future. Int. Rev. Neurobiol. 89, 1-35. doi: 10.1016/S0074-7742(09)89001-6

Lodge, D. J., and Grace, A. A. (2006). The laterodorsal tegmentum is essential for burst firing of ventral tegmental area dopamine neurons. Proc. Natl. Acad. Sci. U.S.A. 103, 5167-5172. doi: 10.1073/pnas.0510715103

London, E. D., Broussolle, E. P., Links, J. M., Wong, D. F., Cascella, N. G., Dannals, R. F., et al. (1990). Morphine-induced metabolic changes in human brain. Studies with positron emission tomography and [fluorine 18] fluorodeoxyglucose. Arch. Gen. Psychiatry 47, 73-81. doi: 10.1001/archpsyc.1990.018101300 75010

Lu, X. Y., Ghasemzadeh, M. B., and Kalivas, P. W. (1998). Expression of D1 receptor, D2 receptor, substance $\mathrm{P}$ and enkephalin messenger RNAs in the neurons projecting from the nucleus accumbens. Neuroscience 82, 767-780. doi: 10.1016/S0306-4522(97)00327-8

Luscher, C. (2013). Cocaine-evoked synaptic plasticity of excitatory transmission in the ventral tegmental area. Cold Spring Harb. Perspect. Med. 3, a012013. doi: 10.1101/cshperspect.a012013

Magura, S., and Rosenblum, A. (2001). Leaving methadone treatment: lessons learned, lessons forgotten, lessons ignored. Mt. Sinai J. Med. 68, 62-74.

Mahler, S. V., Smith, R. J., Moorman, D. E., Sartor, G. C., and Aston-Jones, G. (2012). Multiple roles for orexin/hypocretin in addiction. Prog. Brain Res. 198, 79-121. doi: 10.1016/B978-0-444-59489-1.00007-0
Malinow, R., and Malenka, R. C. (2002). AMPA receptor trafficking and synaptic plasticity. Annu. Rev. Neurosci. 25, 103-126. doi: 10.1146/annurev.neuro.25.112701.142758

Mangiavacchi, S., and Wolf, M. E. (2004). D1 dopamine receptor stimulation increases the rate of AMPA receptor insertion onto the surface of cultured nucleus accumbens neurons through a pathway dependent on protein kinase A. J. Neurochem. 88, 1261-1271. doi: 10.1046/j.1471-4159.2003.02248.x

Mansour, A., Fox, C. A., Akil, H., and Watson, S. J. (1995a). Opioid-receptor mRNA expression in the rat CNS: anatomical and functional implications. Trends Neurosci. 18, 22-29. doi: 10.1016/0166-2236(95)93946-U

Mansour, A., Fox, C. A., Burke, S., Akil, H., and Watson, S. J. (1995b). Immunohistochemical localization of the cloned mu opioid receptor in the rat CNS. J. Chem. Neuroanat. 8, 283-305. doi: 10.1016/0891-0618(95)00055-C

Mansour, A., Fox, C. A., Thompson, R. C., Akil, H., and Watson, S. J. (1994). muOpioid receptor mRNA expression in the rat CNS: comparison to mu-receptor binding. Brain Res. 643, 245-265. doi: 10.1016/0006-8993(94)90031-0

Mansour, A., Khachaturian, H., Lewis, M. E., Akil, H., and Watson, S. J. (1988). Anatomy of CNS opioid receptors. Trends Neurosci. 11, 308-314. doi: 10.1016/0166-2236(88)90093-8

Manzoni, O. J., and Williams, J. T. (1999). Presynaptic regulation of glutamate release in the ventral tegmental area during morphine withdrawal. J. Neurosci. 19, 6629-6636.

Martin, G., Guadano-Ferraz, A., Morte, B., Ahmed, S., Koob, G. F., De Lecea, L., et al. (2004). Chronic morphine treatment alters $N$-methyl-D-aspartate receptors in freshly isolated neurons from nucleus accumbens. J. Pharmacol. Exp. Ther. 311, 265-273. doi: 10.1124/jpet.104.067504

Martin, G., Nie, Z., and Siggins, G. R. (1997). mu-Opioid receptors modulate NMDA receptor-mediated responses in nucleus accumbens neurons. J. Neurosci. $17,11-22$.

Martin, G., Przewlocki, R., and Siggins, G. R. (1999). Chronic morphine treatment selectively augments metabotropic glutamate receptor-induced inhibition of $N$ methyl-D-aspartate receptor-mediated neurotransmission in nucleus accumbens. J. Pharmacol. Exp. Ther. 288, 30-35.

Martin, W. R., and Jasinski, D. R. (1969). Physiological parameters of morphine dependence in man - tolerance, early abstinence, protracted abstinence. J. Psychiatr. Res. 7, 9-17. doi: 10.1016/0022-3956(69)90007-7

Matthes, H. W., Maldonado, R., Simonin, F., Valverde, O., Slowe, S., Kitchen, I., et al. (1996). Loss of morphine-induced analgesia, reward effect and withdrawal symptoms in mice lacking the mu-opioid-receptor gene. Nature 383, 819-823. doi: $10.1038 / 383819 \mathrm{a} 0$

Mattick, R. P., Kimber, J., Breen, C., and Davoli, M. (2008). Buprenorphine maintenance versus placebo or methadone maintenance for opioid dependence. Cochrane Database Syst. Rev. CD002207. doi: 10.1002/14651858.CD0022 07.pub3

Mazei-Robison, M. S., Koo, J. W., Friedman, A. K., Lansink, C. S., Robison, A. J., Vinish, M., et al. (2011). Role for mTOR signaling and neuronal activity in morphine-induced adaptations in ventral tegmental area dopamine neurons. Neuron 72, 977-990. doi: 10.1016/j.neuron.2011.10.012

McFarland, K., and Kalivas, P. W. (2001). The circuitry mediating cocaine-induced reinstatement of drug-seeking behavior. J. Neurosci. 21, 8655-8663.

Mello, N. K., and Negus, S. S. (1996). Preclinical evaluation of pharmacotherapies for treatment of cocaine and opioid abuse using drug self-administration procedures. Neuropsychopharmacology 14, 375-424. doi: 10.1016/0893-133X(95) 00274-H

Mickiewicz, A. L., and Napier, T. C. (2011). Repeated exposure to morphine alters surface expression of AMPA receptors in the rat medial prefrontal cortex. Eur. J. Neurosci. 33, 259-265. doi: 10.1111/j.1460-9568.2010.07502.x

Mink, J. W. (1996). The basal ganglia: focused selection and inhibition of competing motor programs. Prog. Neurobiol. 50, 381-425. doi: 10.1016/S03010082(96)00042-1

Mogenson, G. J., Jones, D. L., and Yim, C. Y. (1980). From motivation to action functional interface between the limbic system and the motor system. Prog. Neurobiol. 14, 69-97. doi: 10.1016/0301-0082(80)90018-0

Monyer, H., Sprengel, R., Schoepfer, R., Herb, A., Higuchi, M., Lomeli, H., et al. (1992). Heteromeric NMDA receptors: molecular and functional distinction of subtypes. Science 256, 1217-1221. doi: 10.1126/science.256.5060.1217

Murray, F., Harrison, N. J., Grimwood, S., Bristow, L. J., and Hutson, P. H. (2007). Nucleus accumbens NMDA receptor subunit expression and function 
is enhanced in morphine-dependent rats. Eur. J. Pharmacol. 562, 191-197. doi: 10.1016/j.ejphar.2007.01.027

Myers, K. M., and Carlezon, W. A. Jr. (2010a). D-Cycloserine facilitates extinction of naloxone-induced conditioned place aversion in morphine-dependent rats. Biol. Psychiatry 67, 85-87. doi: 10.1016/j.biopsych.2009.08.015

Myers, K. M., and Carlezon, W. A. Jr. (2010b). Extinction of drug- and withdrawalpaired cues in animal models: relevance to the treatment of addiction. Neurosci. Biobehav. Rev. 35, 285-302. doi: 10.1016/j.neubiorev.2010.01.011

Nair-Roberts, R. G., Chatelain-Badie, S. D., Benson, E., White-Cooper, H., Bolam, J. P., and Ungless, M. A. (2008). Stereological estimates of dopaminergic, GABAergic and glutamatergic neurons in the ventral tegmental area, substantia nigra and retrorubral field in the rat. Neuroscience 152, 1024-1031. doi: 10.1016/j.neuroscience.2008.01.046

Nestler, E. J., and Aghajanian, G. K. (1997). Molecular and cellular basis of addiction. Science 278, 58-63. doi: 10.1126/science.278.5335.58

Nestler, E. J., and Tallman, J. F. (1988). Chronic morphine treatment increases cyclic AMP-dependent protein kinase activity in the rat locus coeruleus. Mol. Pharmacol. 33, 127-132.

Niehaus, J. L., Murali, M., and Kauer, J. A. (2010). Drugs of abuse and stress impair LTP at inhibitory synapses in the ventral tegmental area. Eur. J. Neurosci. 32, 108-117. doi: 10.1111/j.1460-9568.2010.07256.x

NSDUH. (2013). Results from the 2012 National Survey on Drug Use and Health: Summary of National Findings. Rockville: Substance Abuse and Mental Health Services Administration.

O’Brien, C. P., Ehrman, R. N., and Ternes, J. W. (1986). "Classical conditioning in human opioid dependence," in Behavioral Analysis of Drug Dependence, ed. S. Goldberg (Orlando: Academic Press), 329-356.

Olds, M. E. (1982). Reinforcing effects of morphine in the nucleus accumbens. Brain Res. 237, 429-440. doi: 10.1016/0006-8993(82)90454-1

Paolone, G., Botreau, F., and Stewart, J. (2009). The facilitative effects of Dcycloserine on extinction of a cocaine-induced conditioned place preference can be long lasting and resistant to reinstatement. Psychopharmacology (Berl.) 202, 403-409. doi: 10.1007/s00213-008-1280-y

Pasternak, G. W. (2012). Preclinical pharmacology and opioid combinations. Pain Med. 13(Suppl. 1), S4-S11. doi: 10.1111/j.1526-4637.2012.01335.x

Peoples, L. L., and West, M. O. (1996). Phasic firing of single neurons in the rat nucleus accumbens correlated with the timing of intravenous cocaine self-administration. J. Neurosci. 16, 3459-3473.

Pettit, H. O., Ettenberg, A., Bloom, F. E., and Koob, G. F. (1984). Destruction of dopamine in the nucleus accumbens selectively attenuates cocaine but not heroin self-administration in rats. Psychopharmacology (Berl.) 84, 167-173. doi: 10.1007/BF00427441

Pierce, R. C., and Wolf, M. E. (2013). Psychostimulant-induced neuroadaptations in nucleus accumbens AMPA receptor transmission. Cold Spring Harb. Perspect. Med. 3, a012021. doi: 10.1101/cshperspect. a012021

Popik, P., and Kolasiewicz, W. (1999). Mesolimbic NMDA receptors are implicated in the expression of conditioned morphine reward. Naunyn Schmiedebergs Arch. Pharmacol. 359, 288-294. doi: 10.1007/PL00005354

Reimers, J. M., Milovanovic, M., and Wolf, M. E. (2011). Quantitative analysis of AMPA receptor subunit composition in addiction-related brain regions. Brain Res. 1367, 223-233. doi: 10.1016/j.brainres.2010.10.016

Reynolds, S. M., and Berridge, K. C. (2002). Positive and negative motivation in nucleus accumbens shell: bivalent rostrocaudal gradients for GABA-elicited eating, taste "liking"/“disliking" reactions, place preference/avoidance, and fear. $J$. Neurosci. 22, 7308-7320.

Robbe, D., Alonso, G., Chaumont, S., Bockaert, J., and Manzoni, O. J. (2002a) Role of $\mathrm{p} / \mathrm{q}-\mathrm{Ca}^{2+}$ channels in metabotropic glutamate receptor 2/3-dependent presynaptic long-term depression at nucleus accumbens synapses. J. Neurosci. 22, 4346-4356.

Robbe, D., Bockaert, J., and Manzoni, O. J. (2002b). Metabotropic glutamate receptor 2/3-dependent long-term depression in the nucleus accumbens is blocked in morphine withdrawn mice. Eur. J. Neurosci. 16, 2231-2235. doi: 10.1046/j.1460-9568.2002.02273.x

Rodriguez-Munoz, M., Sanchez-Blazquez, P., Vicente-Sanchez, A., Berrocoso, E., and Garzon, J. (2012). The mu-opioid receptor and the NMDA receptor associate in PAG neurons: implications in pain control. Neuropsychopharmacology 37, 338349. doi: 10.1038/npp.2011.155
Rogawski, M. A., and Loscher, W. (2004). The neurobiology of antiepileptic drugs. Nat. Rev. Neurosci. 5, 553-564. doi: 10.1038/nrn1430

Roitman, M. F., Wheeler, R. A., and Carelli, R. M. (2005). Nucleus accumbens neurons are innately tuned for rewarding and aversive taste stimuli, encode their predictors, and are linked to motor output. Neuron 45, 587-597. doi: 10.1016/j.neuron.2004.12.055

Rossetti, Z. L., Hmaidan, Y., and Gessa, G. L. (1992). Marked inhibition of mesolimbic dopamine release: a common feature of ethanol, morphine, cocaine and amphetamine abstinence in rats. Eur. J. Pharmacol. 221, 227-234. doi: 10.1016/0014-2999(92)90706-A

Rothwell, P. E., Thomas, M. J., and Gewirtz, J. C. (2012). Protracted manifestations of acute dependence after a single morphine exposure. Psychopharmacology (Berl.) 219, 991-998. doi: 10.1007/s00213-011-2425-y

Saal, D., Dong, Y., Bonci, A., and Malenka, R. C. (2003). Drugs of abuse and stress trigger a common synaptic adaptation in dopamine neurons. Neuron 37, 577-582. doi: 10.1016/S0896-6273(03)00021-7

Salamone, J. D., and Correa, M. (2012). The mysterious motivational functions of mesolimbic dopamine. Neuron 76, 470-485. doi: 10.1016/j.neuron.2012. 10.021

Schildein, S., Agmo, A., Huston, J. P., and Schwarting, R. K. (1998). Intraaccumbens injections of substance $\mathrm{P}$, morphine and amphetamine: effects on conditioned place preference and behavioral activity. Brain Res. 790, 185-194. doi: 10.1016/S0006-8993(98)00062-6

Schilstrom, B., Yaka, R., Argilli, E., Suvarna, N., Schumann, J., Chen, B. T., et al. (2006). Cocaine enhances NMDA receptor-mediated currents in ventral tegmental area cells via dopamine D5 receptor-dependent redistribution of NMDA receptors. J. Neurosci. 26, 8549-8558. doi: 10.1523/JNEUROSCI.517905.2006

Schlaepfer, T. E., Strain, E. C., Greenberg, B. D., Preston, K. L., Lancaster, E., Bigelow, G. E., et al. (1998). Site of opioid action in the human brain: mu and kappa agonists' subjective and cerebral blood flow effects. Am. J. Psychiatry 155, $470-473$.

Schlosburg, J. E., Whitfield, T. W. Jr., Park, P. E., Crawford, E. F., George, O., Vendruscolo, L. F., et al. (2013). Long-term antagonism of kappa opioid receptors prevents escalation of and increased motivation for heroin intake. J. Neurosci. 33, 19384-19392. doi: 10.1523/JNEUROSCI.1979-13.2013

Seeburg, P. H. (1993). The TINS/TiPS Lecture. The molecular biology of mammalian glutamate receptor channels. Trends Neurosci. 16, 359-365. doi: 10.1016/0166-2236(93)90093-2

Seeburg, P. H., Burnashev, N., Kohr, G., Kuner, T., Sprengel, R., and Monyer, H. (1995). The NMDA receptor channel: molecular design of a coincidence detector. Recent Prog. Horm. Res. 50, 19-34.

Self, D. W., Mcclenahan, A. W., Beitner-Johnson, D., Terwilliger, R. Z., and Nestler, E. J. (1995). Biochemical adaptations in the mesolimbic dopamine system in response to heroin self-administration. Synapse 21, 312-318. doi: $10.1002 /$ syn. 890210405

Sepulveda, J., Oliva, P., and Contreras, E. (2004). Neurochemical changes of the extracellular concentrations of glutamate and aspartate in the nucleus accumbens of rats after chronic administration of morphine. Eur. J. Pharmacol. 483, 249-258. doi: 10.1016/j.ejphar.2003.10.037

Sepulveda, M. J., Hernandez, L., Rada, P., Tucci, S., and Contreras, E. (1998). Effect of precipitated withdrawal on extracellular glutamate and aspartate in the nucleus accumbens of chronically morphine-treated rats: an in vivo microdialysis study. Pharmacol. Biochem. Behav. 60, 255-262. doi: 10.1016/S0091-3057(97) 00550-9

Sesack, S. R., and Grace, A. A. (2010). Cortico-basal ganglia reward network: microcircuitry. Neuropsychopharmacology 35, 27-47. doi: 10.1038/npp. 2009.93

Shabat-Simon, M., Levy, D., Amir, A., Rehavi, M., and Zangen, A. (2008). Dissociation between rewarding and psychomotor effects of opiates: differential roles for glutamate receptors within anterior and posterior portions of the ventral tegmental area. J. Neurosci. 28, 8406-8416. doi: 10.1523/JNEUROSCI.195808.2008

Shalev, U., Grimm, J. W., and Shaham, Y. (2002). Neurobiology of relapse to heroin and cocaine seeking: a review. Pharmacol. Rev. 54, 1-42. doi: 10.1124/pr. 54.1.1

Shaw-Lutchman, T. Z., Barrot, M., Wallace, T., Gilden, L., Zachariou, V., Impey, S., et al. (2002). Regional and cellular mapping of cAMP response element-mediated 
transcription during naltrexone-precipitated morphine withdrawal. J. Neurosci. $22,3663-3672$

Shen, H., and Kalivas, P. W. (2013). Reduced LTP and LTD in prefrontal cortex synapses in the nucleus accumbens after heroin self-administration. Int. J. Neuropsychopharmacol. 16, 1165-1167. doi: 10.1017/S1461145712001071

Shen, H., Moussawi, K., Zhou, W., Toda, S., and Kalivas, P. W. (2011). Heroin relapse requires long-term potentiation-like plasticity mediated by NMDA2bcontaining receptors. Proc. Natl. Acad. Sci. U.S.A. 108, 19407-19412. doi: 10.1073/pnas.1112052108

Shi, J., Li, S. X., Zhang, X. L., Wang, X., Le Foll, B., Zhang, X. Y., et al. (2009). Time-dependent neuroendocrine alterations and drug craving during the first month of abstinence in heroin addicts. Am. J. Drug Alcohol Abuse 35, 267-272. doi: 10.1080/00952990902933878

Sigmon, S. C., Dunn, K. E., Saulsgiver, K., Patrick, M. E., Badger, G. J., Heil, S. H., et al. (2013). A randomized, double-blind evaluation of buprenorphine taper duration in primary prescription opioid abusers. JAMA Psychiatry 70, 1347-1354. doi: 10.1001/jamapsychiatry.2013.2216

Snyder, G. L., Galdi, S., Fienberg, A. A., Allen, P., Nairn, A. C., and Greengard, P. (2003). Regulation of AMPA receptor dephosphorylation by glutamate receptor agonists. Neuropharmacology 45, 703-713. doi: 10.1016/S0028-3908(03) 00319-8

Sommer, B., Kohler, M., Sprengel, R., and Seeburg, P. H. (1991). RNA editing in brain controls a determinant of ion flow in glutamate-gated channels. Cell 67, 11-19. doi: 10.1016/0092-8674(91)90568-J

Song, I., and Huganir, R. L. (2002). Regulation of AMPA receptors during synaptic plasticity. Trends Neurosci. 25, 578-588. doi: 10.1016/S0166-2236(02) 02270-1

Spijker, S., Houtzager, S. W., De Gunst, M. C., De Boer, W. P., Schoffelmeer, A. N., and Smit, A. B. (2004). Morphine exposure and abstinence define specific stages of gene expression in the rat nucleus accumbens. FASEB J. 18, 848-850. doi: 10.1096/fj.03-0612fje

Stewart, J., De Wit, H., and Eikelboom, R. (1984). Role of unconditioned and conditioned drug effects in the self-administration of opiates and stimulants. Psychol. Rev. 91, 251-268. doi: 10.1037/0033-295X.91.2.251

Stinus, L., Le Moal, M., and Koob, G. F. (1990). Nucleus accumbens and amygdala are possible substrates for the aversive stimulus effects of opiate withdrawal. Neuroscience 37, 767-773. doi: 10.1016/0306-4522(90)90106-E

Straub, C., and Tomita, S. (2012). The regulation of glutamate receptor trafficking and function by TARPs and other transmembrane auxiliary subunits. Curr. Opin. Neurobiol. 22, 488-495. doi: 10.1016/j.conb.2011.09.005

Surmeier, D. J., Ding, J., Day, M., Wang, Z., and Shen, W. (2007). D1 and D2 dopamine-receptor modulation of striatal glutamatergic signaling in striatal medium spiny neurons. Trends Neurosci. 30, 228-235. doi: 10.1016/j.tins.2007.03.008

Suto, N., Wise, R. A., and Vezina, P. (2011). Dorsal as well as ventral striatal lesions affect levels of intravenous cocaine and morphine self-administration in rats. Neurosci. Lett. 493, 29-32. doi: 10.1016/j.neulet.2011.02.011

Svingos, A. L., Garzon, M., Colago, E. E., and Pickel, V. M. (2001). Mu-opioid receptors in the ventral tegmental area are targeted to presynaptically and directly modulate mesocortical projection neurons. Synapse 41, 221-229. doi: 10.1002/syn.1079

Swanson, L. W. (1982). The projections of the ventral tegmental area and adjacent regions: a combined fluorescent retrograde tracer and immunofluorescence study in the rat. Brain Res. Bull. 9, 321-353. doi: 10.1016/0361-9230(82) 90145-9

Takahashi, T., Svoboda, K., and Malinow, R. (2003). Experience strengthening transmission by driving AMPA receptors into synapses. Science 299, 1585-1588. doi: 10.1126/science.1079886

Tang, Y. P., Shimizu, E., Dube, G. R., Rampon, C., Kerchner, G. A., Zhuo, M., et al. (1999). Genetic enhancement of learning and memory in mice. Nature 401, 63-69. doi: 10.1038/43432

Tenorio, G., Connor, S. A., Guevremont, D., Abraham, W. C., Williams, J., O’Dell, T. J., et al. (2010). 'Silent' priming of translation-dependent LTP by ss-adrenergic receptors involves phosphorylation and recruitment of AMPA receptors. Learn. Mem. 17, 627-638. doi: 10.1101/lm.1974510

Tepper, J. M., Martin, L. P., and Anderson, D. R. (1995). GABAA receptor-mediated inhibition of rat substantia nigra dopaminergic neurons by pars reticulata projection neurons. J. Neurosci. 15, 3092-3103.
Terwilliger, R. Z., Beitner-Johnson, D., Sevarino, K. A., Crain, S. M., and Nestler, E. J. (1991). A general role for adaptations in G-proteins and the cyclic AMP system in mediating the chronic actions of morphine and cocaine on neuronal function. Brain Res. 548, 100-110. doi: 10.1016/0006-8993(91)91111-D

The National Center on Addiction and Substance Abuse, Columbia University. (2011). Adolescent Substance Use: America's \#1 Public Health Problem. New York: Columbia University.

Todtenkopf, M. S., Parsegian, A., Naydenov, A., Neve, R. L., Konradi, C., and Carlezon, W. A. Jr. (2006). Brain reward regulated by AMPA receptor subunits in nucleus accumbens shell. J. Neurosci. 26, 11665-11669. doi: 10.1523/JNEUROSCI.3070-06.2006

Tokuyama, S., Wakabayashi, H., and Ho, I. K. (1996). Direct evidence for a role of glutamate in the expression of the opioid withdrawal syndrome. Eur. J. Pharmacol. 295, 123-129. doi: 10.1016/0014-2999(95)00645-1

Trujillo, K. A. (2002). The neurobiology of opiate tolerance, dependence and sensitization: mechanisms of NMDA receptor-dependent synaptic plasticity. Neurotox. Res. 4, 373-391. doi: 10.1080/10298420290023954

Trujillo, K. A., and Akil, H. (1991). Inhibition of morphine tolerance and dependence by the NMDA receptor antagonist MK-801. Science 251, 85-87. doi: $10.1126 /$ science. 1824728

Turrigiano, G. G. (2008). The self-tuning neuron: synaptic scaling of excitatory synapses. Cell 135, 422-435. doi: 10.1016/j.cell.2008.10.008

Ungless, M. A., Whistler, J. L., Malenka, R. C., and Bonci, A. (2001). Single cocaine exposure in vivo induces long-term potentiation in dopamine neurons. Nature 411, 583-587. doi: 10.1038/35079077

Vaccarino, F. J., Bloom, F. E., and Koob, G. F. (1985). Blockade of nucleus accumbens opiate receptors attenuates intravenous heroin reward in the rat. Psychopharmacology (Berl.) 86, 37-42. doi: 10.1007/BF00431681

Van Vliet, B. J., De Vries, T. J., Wardeh, G., Mulder, A. H., and Schoffelmeer, A. N. (1991). mu-Opioid receptor-regulated adenylate cyclase activity in primary cultures of rat striatal neurons upon chronic morphine exposure. Eur. J. Pharmacol. 208, 105-111. doi: 10.1016/0922-4106(91)90060-U

Vekovischeva, O. Y., Zamanillo, D., Echenko, O., Seppala, T., Uusi-Oukari, M., Honkanen, A., et al. (2001). Morphine-induced dependence and sensitization are altered in mice deficient in AMPA-type glutamate receptor-A subunits. J. Neurosci. 21, 4451-4459.

Volman, S. F., Lammel, S., Margolis, E. B., Kim, Y., Richard, J. M., Roitman, M. F., et al. (2013). New insights into the specificity and plasticity of reward and aversion encoding in the mesolimbic system. J. Neurosci. 33, 17569-17576. doi: 10.1523/JNEUROSCI.3250-13.2013

Waldhoer, M., Bartlett, S. E., and Whistler, J. L. (2004). Opioid receptors. Annu. Rev. Biochem. 73, 953-990. doi: 10.1146/annurev.biochem.73.011303.073940

Weiner, D. M., Levey, A. I., Sunahara, R. K., Niznik, H. B., O’Dowd, B. F., Seeman, P., et al. (1991). D1 and D2 dopamine receptor mRNA in rat brain. Proc. Natl. Acad. Sci. U.S.A. 88, 1859-1863. doi: 10.1073/pnas.88.5.1859

Weinshenker, D., and Schroeder, J. P. (2007). There and back again: a tale of norepinephrine and drug addiction. Neuropsychopharmacology 32, 1433-1451. doi: 10.1038/sj.npp. 1301263

Weiss, R. D., Potter, J. S., Fiellin, D. A., Byrne, M., Connery, H. S., Dickinson, W., etal. (2011). Adjunctive counseling during brief and extended buprenorphine-naloxone treatment for prescription opioid dependence: a 2phase randomized controlled trial. Arch. Gen. Psychiatry 68, 1238-1246. doi: 10.1001/archgenpsychiatry.2011.121

Wenthold, R. J., Petralia, R. S., Blahos, J., Ii., and Niedzielski, A. S. (1996). Evidence for multiple AMPA receptor complexes in hippocampal CA1/CA2 neurons. J. Neurosci. 16, 1982-1989.

Wheeler, R. A., and Carelli, R. M. (2009). Dissecting motivational circuitry to understand substance abuse. Neuropharmacology 56(Suppl. 1), 149-159. doi: 10.1016/j.neuropharm.2008.06.028

Wikler, A. (1973). Dynamics of drug dependence. Implications of a conditioning theory for research and treatment. Arch. Gen. Psychiatry 28, 611-616. doi: 10.1001/archpsyc.1973.01750350005001

Williams, J. T., Christie, M. J., and Manzoni, O. (2001). Cellular and synaptic adaptations mediating opioid dependence. Physiol. Rev. 81, 299-343.

Williams, J. T., Ingram, S. L., Henderson, G., Chavkin, C., Von Zastrow, M., Schulz, S., et al. (2013). Regulation of mu-opioid receptors: desensitization, phosphorylation, internalization, and tolerance. Pharmacol. Rev. 65, 223-254. doi: $10.1124 /$ pr.112.005942 
Wilson, C. J., and Groves, P. M. (1980). Fine structure and synaptic connections of the common spiny neuron of the rat neostriatum: a study employing intracellular inject of horseradish peroxidase. J. Comp. Neurol. 194, 599-615. doi: 10.1002/cne.901940308

Wise, R. A. (1989). Opiate reward: sites and substrates. Neurosci. Biobehav. Rev. 13, 129-133. doi: 10.1016/S0149-7634(89)80021-1

Wise, R. A. (2004). Dopamine, learning and motivation. Nat. Rev. Neurosci. 5, 483-494. doi: 10.1038/nrn1406

Wolf, M. E. (2010). Regulation of AMPA receptor trafficking in the nucleus accumbens by dopamine and cocaine. Neurotox. Res. 18, 393-409. doi: 10.1007/s12640-010-9176-0

Wolf, M. E., Mangiavacchi, S., and Sun, X. (2003). Mechanisms by which dopamine receptors may influence synaptic plasticity. Ann. N. Y. Acad. Sci. 1003, 241-249. doi: 10.1196/annals.1300.015

Wolf, M. E., Sun, X., Mangiavacchi, S., and Chao, S. Z. (2004). Psychomotor stimulants and neuronal plasticity. Neuropharmacology 47(Suppl. 1), 61-79. doi: 10.1016/j.neuropharm.2004.07.006

Woody, G. E., Poole, S. A., Subramaniam, G., Dugosh, K., Bogenschutz, M., Abbott, P., et al. (2008). Extended vs short-term buprenorphine-naloxone for treatment of opioid-addicted youth: a randomized trial. JAMA 300, 2003-2011. doi: $10.1001 /$ jama.2008.574

Xi, Z. X., and Stein, E. A. (2002). Blockade of ionotropic glutamatergic transmission in the ventral tegmental area reduces heroin reinforcement in rat. Psychopharmacology (Berl.) 164, 144-150. doi: 10.1007/s00213-002-1190-3

Yuferov, V., Fussell, D., Laforge, K. S., Nielsen, D. A., Gordon, D., Ho, A., et al. (2004) Redefinition of the human kappa opioid receptor gene (OPRK1) structure and association of haplotypes with opiate addiction. Pharmacogenetics 14, 793-804. doi: 10.1097/00008571-200412000-00002
Zahm, D. S., and Brog, J. S. (1992). On the significance of subterritories in the "accumbens" part of the rat ventral striatum. Neuroscience 50, 751-767. doi: 10.1016/0306-4522(92)90202-D

Zahm, D. S., and Heimer, L. (1990). Two transpallidal pathways originating in the rat nucleus accumbens. J. Comp. Neurol. 302, 437-446. doi: 10.1002/cne.903020302

Zito, K. A., Vickers, G., and Roberts, D. C. (1985). Disruption of cocaine and heroin self-administration following kainic acid lesions of the nucleus accumbens. Pharmacol. Biochem. Behav. 23, 1029-1036. doi: 10.1016/0091-3057(85)90110-8 Zullino, D. F., Krenz, S., Zimmerman, G., Miozzari, A., Rajeswaran, R., Kolly, S., et al. (2004). Topiramate in opiate withdrawal - comparison with clonidine and with carbamazepine/mianserin. Subst. Abus. 25, 27-33. doi: 10.1300/J465v25n04_04

Conflict of Interest Statement: The authors declare that the research was conducted in the absence of any commercial or financial relationships that could be construed as a potential conflict of interest.

Received: 26 February 2014; accepted: 30 April 2014; published online: 27 May 2014. Citation: Chartoff EH and Connery HS (2014) It's MORe exciting than mu: crosstalk between mu opioid receptors and glutamatergic transmission in the mesolimbic dopamine system. Front. Pharmacol. 5:116. doi: 10.3389/fphar.2014.00116

This article was submitted to Neuropharmacology, a section of the journal Frontiers in Pharmacology.

Copyright (c) 2014 Chartoff and Connery. This is an open-access article distributed under the terms of the Creative Commons Attribution License (CC BY). The use, distribution or reproduction in other forums is permitted, provided the original author(s) or licensor are credited and that the original publication in this journal is cited, in accordance with accepted academic practice. No use, distribution or reproduction is permitted which does not comply with these terms. 